\title{
Entre 'estruturas e pontas': o contexto arqueológico do Alto Vale do Itajaí do Sul e o povoamento do Brasil meridional
}

\section{Between 'pits and points': the archaeological context of the Upper Vale do Itajaí do Sul and the settlement of southern Brazil}

\author{
Lucas Bond Reis', "I, Fernando Silva de Almeidal', Lucas Reis Bueno' \\ 'Universidade Federal de Santa Catarina. Florianópolis, Santa Catarina, Brasil \\ "The University of Arizona. Tucson, Arizona, Estados Unidos
}

\begin{abstract}
Resumo: $\bigcirc$ artigo apresenta uma síntese do contexto arqueológico do Alto Vale do Itajaí do Sul, área serrana localizada entre o litoral e o planalto de Santa Catarina, a partir de uma revisão na literatura arqueológica e de dados obtidos em atividades de campo. Há mais de uma centena de sítios arqueológicos nesta área, indicando grande diversidade em termos de implantação, de conjunto artefatual, de cronologia e de associação cultural. A partir de uma comparação entre o contexto arqueológico desta área com áreas adjacentes, procuramos inserir a região do Alto Vale do Itajaí nas discussões mais amplas sobre processo de ocupação do Brasil meridional.
\end{abstract}

Palavras-chave: Itajaí do Sul. Jê meridionais. Tradição Umbu.

\begin{abstract}
This paper presents a summary of the archaeological context in the Upper Itajaí do Sul Valley, an area located between the coast and the Santa Catarina plateau, based on a review of archaeological literature and data obtained from field activities. There are more than a hundred archeological sites in this area, suggesting great diversity in terms of settlement, artifact assemblages, chronology, and cultural association. By comparing the archaeological context of this area with adjacent areas, an attempt is made to insert the Upper Itajaí do Sul Valley into broader discussions about the occupation process of southern Brazil.
\end{abstract}

Keywords: Itajaí do Sul. Southern Jê. Umbu tradition.

\begin{abstract}
REIS, Lucas Bond; ALMEIDA, Fernando Silva de; BUENO, Lucas Reis. Entre 'estruturas e pontas': o contexto arqueológico do Alto Vale do Itajaí do Sul e o povoamento do Brasil meridional. Boletim do Museu Paraense Emílio Goeldi. Ciências Humanas, v. 13, n. 3, p. 597-623, set.-dez. 2018. DOI: http://dx.doi.org/10.1590/1981.81222018000300007.

Autor para correspondência: Lucas Bond Reis. Universidade Federal de Santa Catarina. Laboratório de Estudos Interdisciplinares em Arqueologia. Campus Universitário Trindade, s/n. Florianópolis, SC, Brasil. CEP 88040-900 (lucasbondreis@gmail.com). ORCID: http:// orcid.org/0000-0001-5897-1721.

Recebido em 05/04/2018
\end{abstract}

Aprovado em 04/07/2018 


\section{INTRODUÇÃO}

Desde meados do século XIX, com as primeiras pesquisas sistemáticas em sítios arqueológicos, a região Sul chamou atenção de estudiosos e de pesquisadores, desempenhando papel central no desenvolvimento da disciplina no Brasil (Mendonça de Souza, 1991). Este interesse esteve voltado durante muito tempo para a ocupação litorânea, com estudos sobre sambaquis (Barreto, 1999-2000). Ao longo do século $X X$, com o incremento das pesquisas arqueológicas no país, outros temas surgiram, entre os quais destaca-se o interesse pelas pontas de projétil, pela ocupação de grupos caçadores-coletores em áreas de florestas e campo aberto e pelos sítios cerâmicos, que, no caso do Sul do Brasil, estariam associados a uma ocupação vinculada a povos Tupi, mais especificamente grupos Guarani (Noelli, 1999-2000). Com estes temas, ganhavam destaque os vales de rios de grande porte e a faixa litorânea.

A partir da segunda metade do século $X X$, com a descoberta de vários sítios arqueológicos marcados pela presença de estruturas subterrâneas, o planalto meridional começou também a assumir papel de destaque nas pesquisas realizadas na região Sul do país (Reis, 2015). Com este desenvolvimento, a arqueologia do Sul do Brasil, de certa forma, consolidou categorias de análise e de classificação, associando-as a compartimentos da paisagem regional, construindo, com raras exceções, visões um tanto monolíticas com relação à dinâmica trajetória histórica de ocupação, de interação e de transformação cultural, desenvolvida nesta região das terras baixas sulamericanas ao longo do Holoceno. Estas categorizações geraram, entre outros fatores, ausência de pesquisas para toda área do Sul do Brasil, a qual corresponde à encosta, que abarca toda a borda ocidental das serras Geral e do Mar. Nesta área, apesar da exiguidade de trabalhos, encontramos grande diversidade de sítios, entre os quais podemos mencionar, por exemplo, sambaquis, estruturas subterrâneas, sítios com montículos, estruturas anelares, abrigos sob rochas e sítios líticos com distintas composições (Rohr, 1984; Piazza, 1966; Schmitz, 1991).
Apresentamos, neste artigo, uma síntese de informações acerca do contexto arqueológico no Alto Vale do Itajaí do Sul, área serrana localizada entre o litoral e o planalto de Santa Catarina, a partir de uma revisão na literatura arqueológica e de dados obtidos em atividades de campo, com vistas a contribuir para este debate, chamando a atenção para a área de encosta de Santa Catarina e para a necessidade de discussões relativas a processos de interação cultural.

\section{O ALTO VALE DO RIO ITAJAÍ DO SUL}

O vale do rio Itajaí consiste na maior bacia hidrográfica de Santa Catarina, a principal da vertente atlântica. O mais volumoso curso d'água desta bacia é o Itajái-açu, o qual tem os rios Itajaí do Norte, Itajaí do Oeste e Itajaí do Sul como principais afluentes.

O rio Itajaí do Sul, mais especificamente, possui uma extensão de $84 \mathrm{~km}$, sendo que suas águas percorrem os municípios de Alfredo Wagner, Ituporanga e Aurora até chegar à cidade de Rio do Sul, onde se encontra com o rio Itajaí do Oeste, formando, assim, o Itajaí-açu.

A área que denominamos como Alto Vale do Rio Itajaí do Sul consiste, em síntese, no território municipal de Alfredo Wagner. O rio Itajaí do Sul tem sua origem no encontro dos rios Adaga e Caeté, ocorrendo nas proximidades da área central do município.

Benedet et al. (2008) mostram que a geomorfologia local pode ser sintetizada em duas unidades. A primeira, classificada como patamares do alto rio Itajaí, predomina na área municipal, sendo que consiste em "[...] escarpas, interrompidas por patamares, alternando-se, encostas e patamares até a paisagem estabilizar-se em relevo plano/ ondulado nos vales abertos dos rios [...]" (Benedet et al., 2008, p. 84), composta, essencialmente, por litologia sedimentar. Entrementes, por ocasião do relevo encaixado, percebe-se a exposição do embasamento cristalino no fundo dos vales. Esta unidade apresenta grande amplitude altimétrica entre o topo dos morros e os fundos dos vales (Benedet et al., 2008). A segunda, denominada de planalto 
de Lages, concentra-se no limite sudoeste de Alfredo Wagner, onde a altitude predominante fica entre 850 e $900 \mathrm{~m}$. Essa unidade tem suas vertentes direcionadas para o interior, com deságue no rio Canoas.

Quanto à vegetação, duas formações são predominantes: Mata Atlântica (floresta ombrófila densa) e Mata de Araucárias (floresta ombrófila mista). Enquanto que a primeira se faz presente, sobretudo, nas altitudes mais baixas, a segunda é percebida nas áreas de maiores cotas altimétricas.

\section{HISTÓRICO DAS PESQUISAS ARQUEOLÓGICAS}

Poucas foram as atividades sistemáticas de pesquisa arqueológica realizadas nessa porção da serra catarinense, há, no entanto, mais de cem sítios arqueológicos identificados nessa área. Essa amostra é resultado de estudos pontuais, realizados principalmente ao longo da segunda metade do século $X X$, mas se deve, sobretudo, a informações coletadas pelo Sr. Altair Wagner, morador da região, interessado pela preservação e pela promoção do patrimônio arqueológico local (Wagner, 2002).

O primeiro levantamento de informações acerca da existência de sítios arqueológicos em Alfredo Wagner foi realizado por Walter Piazza, no início da década de 1960. Conforme anotações existentes em diário de campo do pesquisador, em junho de 1966, três sítios foram catalogados no município. As informações sobre cada contexto também foram sistematizadas e apresentadas em texto elaborado pelo pesquisador, intitulado "Memória arqueológica sobre o Vale do Itajaí (Santa Catarina - Brasil)"1. Os sítios registrados por Piazza (1966) foram SC-VI-13, SC-VI-14 Gruta do Barro Branco e SC-VI-15 - Gruta da Lomba Alta.
No ano seguinte, Rohr (1967) apresentou os resultados das primeiras intervenções sistemáticas feitas em dois sítios arqueológicos neste município: SC-VI-13 e em um sítio composto por nove montículos, na localidade de Demora, não registrado anteriormente.

Posteriormente, Rohr $(1971,1984)$ noticiou, de forma inédita, informações acerca da presença de estruturas subterrâneas em Alfredo Wagner, por meio do registro de dois sítios: SC-Alfredo Wagner-4 - composto por duas depressões no solo, com 3 e 5 m de diâmetro por 2,5 m de profundidade, em que Rohr (1971) coletou líticos lascados e polidos em uma trincheira - e SC-Alfredo Wagner-6 também composto por duas concavidades no solo, mas com 6 a $7 \mathrm{~m}$ de diâmetro por $4 \mathrm{~m}$ de profundidade, sendo que não foram feitas intervenções neste sítio.

Em 1972, Alroíno Eble, professor na Universidade Federal de Santa Catarina (UFSC) e arqueólogo no Museu Universitário (atual MArquE/UFSC), iniciou um projeto de prospecção arqueológica no Alto Vale do Itajaí. Conforme o pesquisador, "[...] num total de sessenta dias de trabalhos de campo foram prospectados mais de uma centena de sítios arqueológicos [...]" (Eble, 1973b, p. 70). Contudo, infelizmente nenhum mapa ou catálogo dos sítios identificados foi gerado ou ao menos encontra-se disponível no acervo do MArquE. Cruzando dados a partir da documentação disponível (Eble, 1973a, 1973b)2, foi possível, no entanto, identificar coleções de dois sítios trabalhados por Eble (1973a, 1973b), localizados no Alto Vale do Itajaí do Sul: SC-VI-25 - Alto Jararaca, cuja coleção é composta, exclusivamente, por vestígios líticos - e SCVI-33 - Alto Jararaca II - abrigo sob-rochas, cuja coleção é composta somente por remanescentes ósseos humanos.

\footnotetext{
1 Ambos, diário e texto, integram hoje o acervo documental do Museu de Arqueologia e Etnologia Professor Oswaldo Rodrigues Cabral, da Universidade Federal de Santa Catarina (MArquE/UFSC).

2 No acervo do MArquE/UFSC, há listas com a nomenclatura dos sítios arqueológicos que tomam por base as coleções compiladas por pesquisadores diversos, as quais seguem a padronização utilizada por Piazza (1966), e constam também tabelas com informações sobre os materiais que compõem as coleções. Desse modo, considerando que a sigla VI significa Vale do Itajaí, e que há semelhança entre nomes de sítios e de cursos de água ou localidades de Alfredo Wagner, por meio de uma atividade dedutiva, acreditamos que as coleções de dois sítios estejam relacionadas a contextos situados no município: SC-VI-25 - Alto Jararaca e SC-VI-33 - Alto Jararaca II.
}

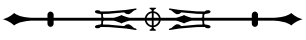


Desde o início da década de 1990, o engenheiro Wagner (2002) efetuou um amplo levantamento arqueológico em Alfredo Wagner, visando identificar e listar vestígios descobertos por moradores, bem como realizou uma atividade de conscientização acerca da preservação do patrimônio arqueológico junto à comunidade. Como resultado, o pesquisador publicou uma lista contendo informações sobre 160 possíveis sítios arqueológicos ${ }^{3}$, entre os quais constam galerias subterrâneas (seis), abrigos sob rochas ${ }^{4}$ (54), 'manchas pretas' (60) e 'casas subterrâneas' (42).

As atividades desenvolvidas por Wagner (2002) resultaram também na fundação do Museu de Arqueologia de Lomba Alta. Centenas de pontas de projétil e de artefatos lascados, polidos e picoteados compõem a maior parte do acervo deste museu. Em meio aos artefatos expostos, um chama a atenção, por ocasião da sua excepcionalidade: um zoólito esculpido no formato de baleia, que foi localizado em Campinho, no interior do município. Há, ainda, uma coleção de remanescentes ósseos humanos, coletados em abrigos sob rochas situados em Alfredo Wagner, e fragmento cerâmico com decoração corrugada - característica de grupos Guarani
-, também coletado no município. Recentemente, a instituição recebeu doação de centenas de fragmentos cerâmicos Guarani, coletados no litoral catarinense por Guilherme Tiburtius.

A partir das informações compiladas por meio de bibliografia e da observação do acervo do museu - que demonstra a diversidade de artefatos já encontrados na região -, optamos por complementar a busca por informações por meio da realização de atividades em campo. Assim, em 2013, a equipe do LEIA/UFSC (2018) iniciou as primeiras atividades de pesquisa em Alfredo Wagner.

Em um primeiro momento, as atividades consistiram no reconhecimento de sítios arqueológicos em campo, sem a realização de intervenções. A partir de 2014, além do reconhecimento, começamos a trabalhar de forma mais intensiva em sítios selecionados e passamos a desenvolver prospecções interventivas na área (Reis, 2015; Almeida, 2015, 2017; Reis et al., 2018).

Como resultado dessas atividades, 38 sítios foram prospectados com ou sem a realização de intervenções, sendo que quatro deles foram escavados: Chapadão Paulo Saturno; Alfredo Henrique Wagner; SC-VI-13/sítio de Alfredo Wagner; e Tobias Wagner (Quadro 1 e Figura 1).

Quadro 1. Sítios prospectados pela equipe LEIA/UFSC em Alfredo Wagner.

(Continua)

\begin{tabular}{|c|c|c|c|c|c|c|}
\hline \multirow{2}{*}{ Número } & \multirow{2}{*}{ Sítio $^{5}$} & $\begin{array}{c}\text { Coordenadas Universal Transversa } \\
\text { de Mercator (UTM), zona 22 }\end{array}$ & \multirow{2}{*}{ Tipo } & Atividade realizada & Referências \\
\cline { 3 - 5 } & Adilson Lopes & 656751 & 6944439 & Lítico a céu aberto & Reconhecimento & Almeida (2017) \\
\hline 1 & $\begin{array}{c}\text { Adolfo } \\
\text { Steinhauser }\end{array}$ & 664105 & 6937157 & Lítico a céu aberto & Reconhecimento & $\begin{array}{c}\text { Wagner (2002); } \\
\text { Reis et al. (2018) }\end{array}$ \\
\hline 3 & Águas Negras & 669179 & 6942203 & Abrigo sob rochas & Reconhecimento & $\begin{array}{c}\text { Wagner (2002); } \\
\text { Almeida (2017) }\end{array}$ \\
\hline 4 & Alexandre & 654078 & 6944218 & Lítico a céu aberto & Reconhecimento & Almeida (2017) \\
\hline
\end{tabular}

3 Alguns foram reconhecidos em campo pela equipe do Laboratório de Estudos Interdisciplinares em Arqueologia/Universidade Federal de Santa Catarina (LEIA/UFSC), conforme o Quadro 1.

4 Wagner (2002, p. 58-59) registrou cavidades rochosas em geral, sem que existissem, necessariamente, vestígios arqueológicos: "Nos abrigos quase sempre encontram-se vestígios de ocupação pelo índio [...]. Nosso objetivo, no momento é cadastrá-las junto ao IPHAN [Instituto do Patrimônio Histórico e Artístico Nacional], e com isso assegurar a pesquisa e protegê-la da destruição".

5 A nomenclatura adotada tem como critério a menção mais antiga em bibliografia.

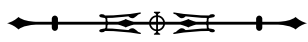


Quadro 1.

(Continua)

\begin{tabular}{|c|c|c|c|c|c|c|}
\hline \multirow[t]{2}{*}{ Número } & \multirow{2}{*}{ Sítio } & \multicolumn{2}{|c|}{$\begin{array}{c}\text { Coordenadas Universal Transversa } \\
\text { de Mercator (UTM), zona 22] }\end{array}$} & \multirow[t]{2}{*}{ Tipo } & \multirow{2}{*}{ Atividade realizada } & \multirow[t]{2}{*}{ Referências } \\
\hline & & $x$ & Y & & & \\
\hline 5 & $\begin{array}{c}\text { Alfredo Henrique } \\
\text { Wagner }\end{array}$ & 659268 & 6931332 & Lítico a céu aberto & Escavação & $\begin{array}{c}\text { Wagner (2002); } \\
\text { Reis (2015); } \\
\text { Almeida (2017) }\end{array}$ \\
\hline 6 & Argentino & 662136 & 6931732 & Abrigo sob rochas & Reconhecimento & Almeida (2017) \\
\hline 7 & Aristides Gukert & 655384 & 6931451 & Lítico a céu aberto & Reconhecimento & $\begin{array}{l}\text { Wagner (2002); } \\
\text { Reis et al. (2018) }\end{array}$ \\
\hline 8 & Arni Mariotti & 656956 & 6938935 & Lítico a céu aberto & Reconhecimento & Almeida (2017) \\
\hline 9 & Balcino Wagner & 663677 & 6935447 & Abrigo sob rochas & $\begin{array}{l}\text { Prospecção } \\
\text { interventiva }\end{array}$ & $\begin{array}{l}\text { Wagner (2002); } \\
\text { Almeida (2017) }\end{array}$ \\
\hline 10 & Caeté & 667317 & 6931296 & Abrigo sob rochas & Reconhecimento & $\begin{array}{l}\text { Wagner (2002); } \\
\text { Reis (2015) }\end{array}$ \\
\hline 11 & Catuíra & 657571 & 6939984 & Abrigo sob rochas & $\begin{array}{l}\text { Prospecção } \\
\text { interventiva }\end{array}$ & $\begin{array}{l}\text { Wagner (2002); } \\
\text { Almeida (2017) }\end{array}$ \\
\hline 12 & $\begin{array}{l}\text { Chapadão Paulo } \\
\text { Saturno }\end{array}$ & 655720 & 6946290 & Lítico a céu aberto & Escavação & $\begin{array}{l}\text { Wagner (2002); } \\
\text { Almeida (2017) }\end{array}$ \\
\hline 13 & Demora & 663734 & 6936478 & Montículos & Reconhecimento & $\begin{array}{c}\text { Rohr (1967); } \\
\text { Reis et al. (2018) }\end{array}$ \\
\hline 14 & Dionleno Mariotti & 658345 & 6941624 & Lítico a céu aberto & Reconhecimento & Almeida (2017) \\
\hline 15 & Edgar Wagner & 663399 & 6934945 & Lítico a céu aberto & Reconhecimento & $\begin{array}{c}\text { Wagner (2002); } \\
\text { Reis (2015); } \\
\text { Almeida (2017) }\end{array}$ \\
\hline 16 & George Wagner & 658313 & 6935050 & $\begin{array}{l}\text { Estruturas } \\
\text { subterrâneas }\end{array}$ & Reconhecimento & $\begin{array}{l}\text { Wagner (2002); } \\
\text { Reis et al. (2018) }\end{array}$ \\
\hline 17 & Indiozinho & 660324 & 6928181 & Abrigo sob rochas & $\begin{array}{l}\text { Prospecção } \\
\text { interventiva }\end{array}$ & $\begin{array}{l}\text { Wagner (2002); } \\
\text { Almeida (2017) }\end{array}$ \\
\hline 18 & Jacó Schüller & 658287 & 6929511 & $\begin{array}{c}\text { Estruturas } \\
\text { subterrâneas }\end{array}$ & Reconhecimento & $\begin{array}{l}\text { Wagner (2002); } \\
\text { Reis et al. (2018) }\end{array}$ \\
\hline 19 & Jairo Wagner & 658682 & 6929882 & $\begin{array}{l}\text { Estruturas } \\
\text { subterrâneas }\end{array}$ & Reconhecimento & $\begin{array}{l}\text { Wagner (2002); } \\
\text { Reis et al. (2018) }\end{array}$ \\
\hline 20 & José Wagner I & 659084 & 6929592 & $\begin{array}{c}\text { Estruturas } \\
\text { subterrâneas }\end{array}$ & Reconhecimento & $\begin{array}{l}\text { Wagner (2002); } \\
\text { Reis (2015) }\end{array}$ \\
\hline 21 & José Wagner II & 658721 & 6928289 & Lítico a céu aberto & Reconhecimento & $\begin{array}{l}\text { Wagner (2002); } \\
\text { Reis (2015); } \\
\text { Almeida (2017) }\end{array}$ \\
\hline 22 & Lauro Mariotti & 663416 & 6928431 & Abrigo sob rochas & Reconhecimento & $\begin{array}{l}\text { Wagner (2002); } \\
\text { Almeida (2017) }\end{array}$ \\
\hline
\end{tabular}

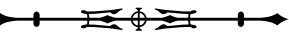


Quadro 1.

(Conclusão)

\begin{tabular}{|c|c|c|c|c|c|c|}
\hline \multirow[t]{2}{*}{ Número } & \multirow[t]{2}{*}{ Sítio } & \multicolumn{2}{|c|}{$\begin{array}{l}\text { Coordenadas Universal Transversa } \\
\text { de Mercator (UTM), zona 22] }\end{array}$} & \multirow[t]{2}{*}{ Tipo } & \multirow[t]{2}{*}{ Atividade realizada } & \multirow[t]{2}{*}{ Referências } \\
\hline & & $x$ & Y & & & \\
\hline 23 & Lomba Alta II & 658466 & 6930949 & Abrigo sob rochas & Reconhecimento & $\begin{array}{l}\text { Wagner (2002); } \\
\quad \text { Reis (2015) }\end{array}$ \\
\hline 24 & Poço Certo & 658709 & 6933027 & Lítico a céu aberto & Registro & Reis (2015) \\
\hline 25 & Poço Certo II & 658667 & 6933283 & $\begin{array}{c}\text { Estruturas } \\
\text { subterrâneas }\end{array}$ & Registro & Reis (2015) \\
\hline 26 & Rio Caixão I & 655831 & 6931701 & $\begin{array}{c}\text { Estruturas } \\
\text { subterrâneas }\end{array}$ & Registro & Reis (2015) \\
\hline 27 & Rio Caixão II & 656589 & 6931185 & $\begin{array}{c}\text { Estruturas } \\
\text { subterrâneas }\end{array}$ & Registro & Reis et al. (2018) \\
\hline 28 & Rio São João I & 659047 & 6928849 & Abrigo sob rochas & Registro & Reis (2015) \\
\hline 29 & Riozinho & 655944 & 6935716 & Abrigo sob rochas & $\begin{array}{l}\text { Prospecção } \\
\text { interventiva }\end{array}$ & $\begin{array}{l}\text { Wagner (2002); } \\
\text { Reis (2015); } \\
\text { Almeida (2017) }\end{array}$ \\
\hline 30 & $\begin{array}{l}\text { Santília Schimidt } \\
\text { Wagner }\end{array}$ & 657722 & 6934998 & $\begin{array}{l}\text { Estruturas } \\
\text { subterrâneas }\end{array}$ & Reconhecimento & $\begin{array}{l}\text { Wagner (2002); } \\
\text { Reis et al. (2018) }\end{array}$ \\
\hline 31 & São Leonardo & 677530 & 6937201 & Abrigo sob rochas & $\begin{array}{l}\text { Prospecção } \\
\text { interventiva }\end{array}$ & Almeida (2017) \\
\hline 32 & $\begin{array}{l}\text { SC-Alfredo } \\
\text { Wagner-6 }\end{array}$ & 658509 & 6933310 & $\begin{array}{c}\text { Estruturas } \\
\text { subterrâneas }\end{array}$ & Reconhecimento & $\begin{array}{l}\text { Rohr (1984); } \\
\text { Wagner (2002); } \\
\text { Reis (2015) }\end{array}$ \\
\hline 33 & $\begin{array}{l}\text { SC-Alfredo } \\
\text { Wagner-4 }\end{array}$ & 663430 & 6935037 & $\begin{array}{c}\text { Estruturas } \\
\text { subterrâneas }\end{array}$ & Reconhecimento & $\begin{array}{l}\text { Rohr (1984); } \\
\text { Wagner (2002); } \\
\text { Reis (2015) }\end{array}$ \\
\hline 34 & $\begin{array}{l}\text { SC-VI-13 - Sítio } \\
\text { de Alfredo } \\
\text { Wagner }\end{array}$ & 663440 & 6934936 & Lítico a céu aberto & Escavação & $\begin{array}{l}\text { Piazza (1966); } \\
\text { Rohr (1984); } \\
\text { Wagner (2002); } \\
\text { Reis (2015); } \\
\text { Almeida (2017) }\end{array}$ \\
\hline 35 & $\begin{array}{l}\text { SC-VI-15 - } \\
\text { Lomba Alta }\end{array}$ & 658356 & 6933537 & Abrigo sob rochas & $\begin{array}{l}\text { Prospecção } \\
\text { interventiva }\end{array}$ & $\begin{array}{c}\text { Piazza (1966); } \\
\text { Rohr (1971, 1984); } \\
\text { Wagner (2002); } \\
\text { Reis (2015); } \\
\text { Almeida (2017) }\end{array}$ \\
\hline 36 & $\begin{array}{l}\text { SC-VI-33 - Alto } \\
\text { Jararaca II }\end{array}$ & 659329 & 6943251 & Abrigo sob rochas & $\begin{array}{l}\text { Prospecção } \\
\text { interventiva }\end{array}$ & $\begin{array}{l}\text { Eble (1973a, 1973b); } \\
\text { De Masi (2001); } \\
\text { Almeida (2017) }\end{array}$ \\
\hline 37 & $\begin{array}{l}\text { Serra do Tio } \\
\text { Zezé }\end{array}$ & 658648 & 6928135 & Abrigo sob rochas & Reconhecimento & $\begin{array}{l}\text { Wagner (2002); } \\
\quad \text { Reis (2015) }\end{array}$ \\
\hline 38 & Tobias Wagner & 658458 & 6932788 & $\begin{array}{c}\text { Estruturas } \\
\text { subterrâneas }\end{array}$ & Escavação & $\begin{array}{l}\text { Wagner (2002); } \\
\quad \text { Reis (2015) }\end{array}$ \\
\hline
\end{tabular}

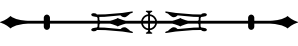



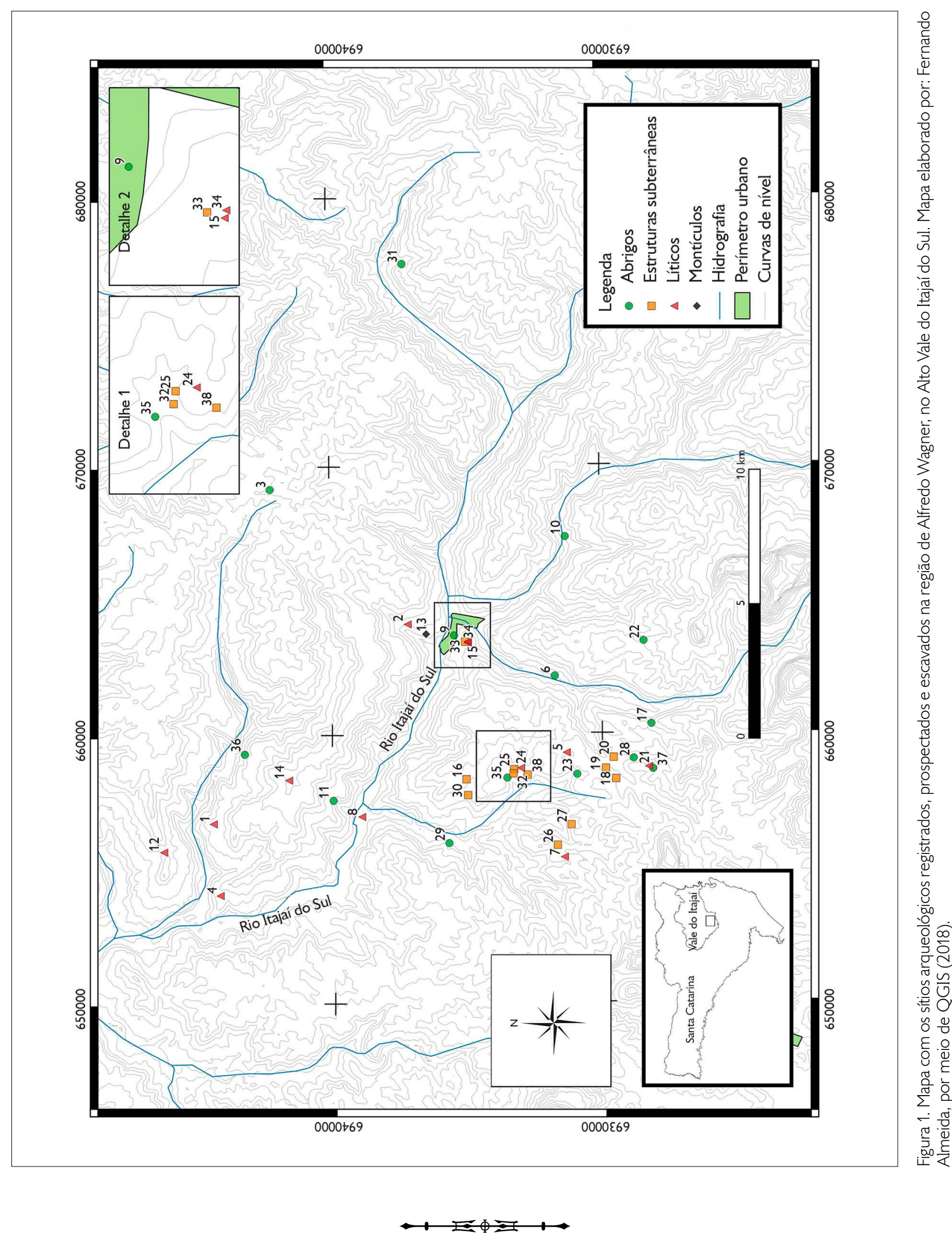


\section{O CONTEXTO ARQUEOLÓGICO NO ALTO VALE DO ITAJAÍ DO SUL}

Aliando o conjunto de informações apresentadas no item anterior, vemos que há quatro categorias de sítios identificadas na região: sítios líticos a céu aberto - também denominados de 'mancha preta' por Wagner (2002) -; abrigos sob rochas - com tamanho e morfologias variados -; sítios compostos por estruturas subterrâneas; e um sítio composto por montículos. $\mathrm{Na}$ Figura 2, constam imagens que exemplificam essas categorias de sítios, excetuando-se o caso do sítio de montículos, que não apresenta mais os aterros por ocasião de atividades antrópicas recentes.

A seguir, serão apresentadas essas categorias, a fim de que, no tópico seguinte, seja discutido o processo de ocupação da área.

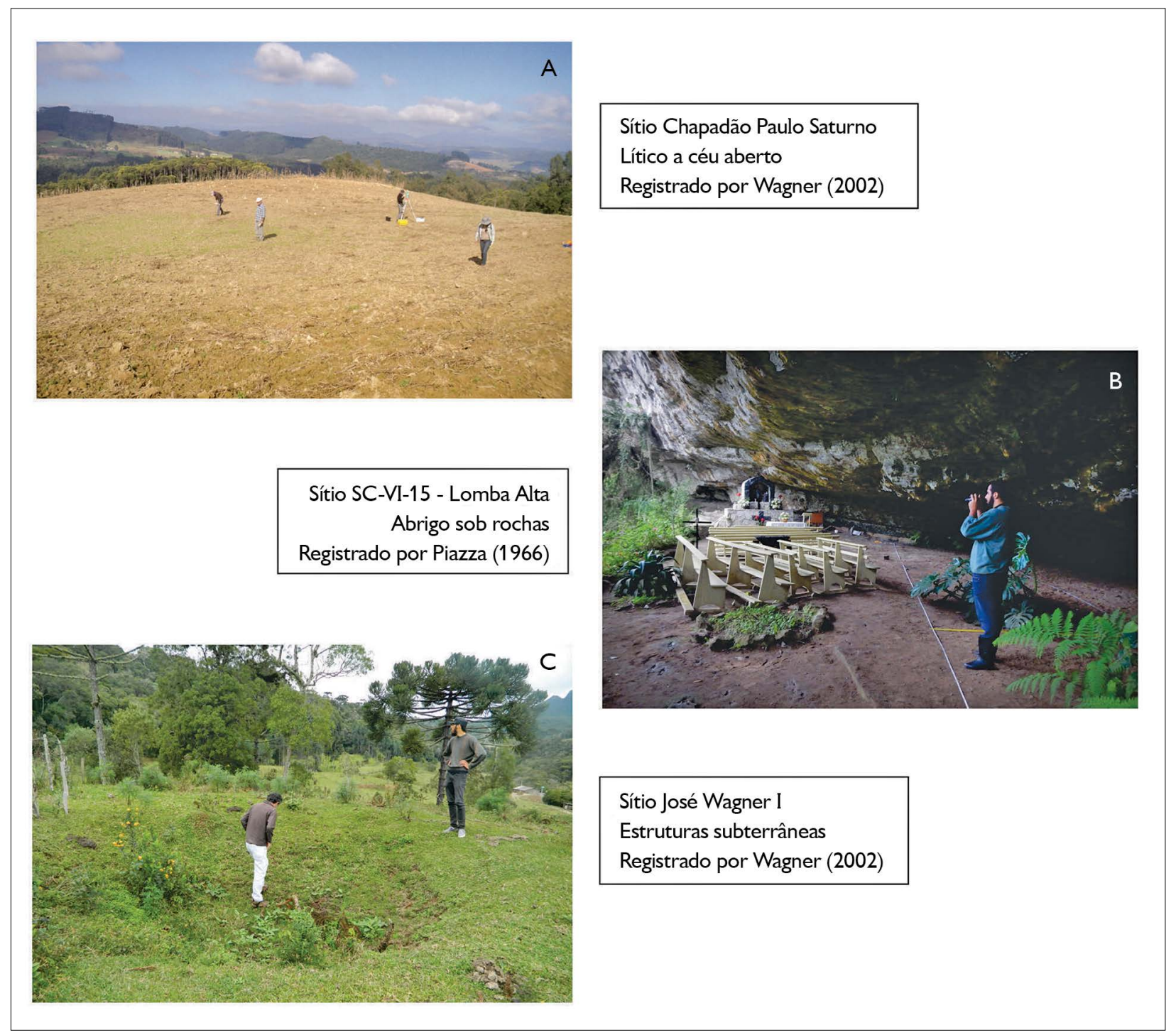

Figura 2. Tipos de sítios arqueológicos registrados no Alto Vale do Itajaí do Sul: A) Sítio Chapadão Paulo Saturno - lítico a céu aberto; B) Sítio SC-VI-15 - Lomba Alta - abrigo sob rochas; C) Sítio José Wagner I - estruturas subterrâneas. Fonte: acervo do LEIA/UFSC. Fotos efetuadas em 2017, 2015 e 2014, respectivamente. Prancha elaborada por Lucas Bond Reis (2018).

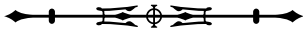




\section{OS SÍTIOS LÍTICOS A CÉU ABERTO}

Os sítios líticos aparecem preferencialmente próximos às cabeceiras dos principais afluentes do rio Itajaí do Sul ou em locais próximos a esses afluentes, em áreas de vertente/ patamares de vertente. Raramente, há ocorrência de sítios também em fundo de vale.

Apesar da grande quantidade de pontas de projétil presente no acervo do Museu de Arqueologia de Lomba Alta e da referência constante por parte dos moradores da região a este tipo de artefato, nem todos os sítios classificados como 'líticos a céu aberto' apresentam em suas coleções este tipo de vestígio (Piazza, 1966; Eble, 1973a, 1973b; Wagner, 2002; Reis, 2015; Almeida, 2017). Dos 60 sítios líticos identificados por Wagner (2002), sabe-se que ao menos 13 apresentam pontas de projétil em suas coleções, sendo que, para os demais, a informação disponível refere-se à presença de vestígios, de fragmentos, de artefatos, sem mais especificações

No sítio SC-VI-13, por exemplo, apesar de Piazza (1966) indicar a presença de pontas de projétil no momento de registro do sítio, tais artefatos não aparecem na coleção resultante das escavações de Rohr (1967). O arqueólogo percebeu duas camadas de ocupação pré-colonial em diferentes profundidades: 80 e $60 \mathrm{~cm}$. Na primeira, encontrou líticos e vestígios de madeira em decomposição. $\mathrm{Na}$ segunda, identificou grande volume de seixos rolados, artefatos líticos, artefatos em madeira, trançados de fibra de Imbé, cascas de árvores e carvão (Rohr, 1967).

As duas camadas de ocupação identificadas por Rohr (1967) nesse sítio apresentam artefatos líticos semelhantes no que concerne à função e às técnicas de transformação do suporte (lascamento, polimento e/ou picoteamento), variando apenas no que diz respeito à frequência (há maior número de artefatos na camada superior). Conforme descrição de Rohr (1967, p. 9):

Entre os artefatos líticos, destacavam-se machados líticos, batedores, amoladores, quebra-coquinhos, pequenas lascas de sílex, núcleos etc. Havia machados de corte alisado, preparados a partir de seixos rolados pelas águas, a maioria deles com evidências de encabamento. Outros machados de corte alisado possuíam cabo solidário; fabricados a partir de prismas alongados e achatados de diabásio.

Segundo Rohr (1967), todos os artefatos líticos foram produzidos a partir de seixos. Em geral, os machados apresentam evidências de lascamento e de polimento, entalhe para encabamento e foram produzidos em diabásio. Acerca dos amoladores, o pesquisador menciona artefatos em basalto e em arenito, sendo identificados por essa função por apresentarem "[...] partes da superfície mais ou menos polidas ou côncavas, em decorrência do desgaste, provocado pelo uso [...]" (Rohr, 1967, p. 17). Os demais tipos de artefatos não são descritos quanto ao tipo de matéria-prima, apenas quanto à função e à forma. A maior parte dos quebra-coquinhos encontrados apresenta a depressão característica em apenas uma das faces, excetuando-se uma peça coletada na camada mais profunda, que contém concavidades em duas faces. Os batedores são percebidos por essa função devido à presença de evidências de desgaste nas extremidades. Há, ainda, uma categoria denominada de miscelânea, a qual compreende artefatos que "[...] apresentam sinais de desbastamento e lascamento em uma ou mais arestas, sendo, no entanto, difícil determinar-lhes a função [...]" (Rohr, 1967, p. 18).

No que tange aos artefatos em fibra e madeira, o pesquisador relata que:
[...] havia belíssimos e finos trançados de fibra de Imbé, que faziam parte de cestinha e duas espirais de fibra de Imbé, que revestiam pontas de arco [...]. Foram encontrados dois artefatos de madeira, superficialmente decompostos, feitos de nós de pinho. Possuíam forma de pregos, de cabeça esférica, de quatro centímetros de espessura. Possuíam quinze a dezesseis centímetros de comprimento. (Rohr, 1967, p. 10).

Para o sítio SC-VI-25, identificado por Eble (1973a, 1973b) e analisado por Farias (2005), os dados apresentados pela pesquisadora indicam a seguinte composição da

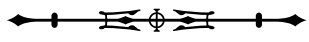


coleção: 14 artefatos, nove lascas, três núcleos, um detrito, 30 blocos naturais e 27 artefatos polidos.

Ao longo dos últimos dois anos, a equipe do LEIA fez intervenções em três sítios líticos no município de Alfredo Wagner: SC-VI-13, Alfredo Henrique Wagner e Chapadão Paulo Saturno, bem como reconheceu ou registrou outros oito sítios (Adilson Lopes, Adolfo Steinhauser, Alexandre, Aristides Gukert, Arni Mariotti, Dionleno Mariotti, Edgar Wagner e José Wagner II).

Entre os sítios escavados, o Alfredo Henrique Wagner localiza-se em uma área de topo. Nesse local, foram encontradas dezenas de pontas bifaciais em uma área de, aproximadamente, $100 \mathrm{~m}^{2}$, coletadas pelo proprietário do terreno, o Sr. Lauro Cunha. Nesse sítio, realizamos duas intervenções, abrindo três unidades de $1 \mathrm{~m}^{2} \mathrm{e}$ uma unidade de $2 \mathrm{~m}^{2}$, escavadas em níveis artificiais. As escavações atingiram a profundidade de $40 \mathrm{~cm}$. O material arqueológico concentrava-se nas primeiras camadas. Não identificamos nenhuma feição indicadora de estruturação espacial na distribuição dos vestígios. Após os trabalhos de campo, realizamos uma análise preliminar dos materiais coletados durante a intervenção e analisamos a coleção particular de pontas de projétil provenientes do mesmo sítio, coletadas pelo Sr. Lauro.

A maioria dos instrumentos identificados no sítio Alfredo Henrique Wagner trata-se de pontas de projétil, mas identificamos também lascas retocadas e um instrumento unifacial. Os instrumentos foram produzidos principalmente a partir da exploração de sílex (46\%), quartzo leitoso (15\%) e arenito silicificado (10\%), obtidos a partir de blocos e, em alguns casos, em seixos, enquanto o restante dos materiais foi produzido em arenito, quartzo hialino, calcedônia e rochas vulcânicas (29\%).

Através de uma classificação ainda exploratória das pontas bifaciais, tanto da coleção particular quanto das coletadas durante a escavação, elas foram agrupadas em quatro categorias, tendo como elemento principal de diferenciação a morfologia do pedúnculo: pontas de pedúnculo bifurcado, convexo, reto e apedunculadas.
Em todas as categorias, é possível encontrar bordas serrilhadas. A partir da existência de uma grande variabilidade de matérias-primas, de formas e de tamanhos de pontas de projétil, verificamos que essas quatro categorias estavam presentes em praticamente todas as pontas analisadas, sendo este o critério utilizado para a sua classificação.

Diferentes autores que trabalham com as variações tecnológicas associadas à formação dos pedúnculos argumentam que as alterações entre esses pedúnculos podem ser interpretadas como estilísticas e seriam relacionadas a variações culturais, porém, essas diferenças também podem ser interpretadas como funcionais, sendo criadas pela necessidade de encabamento ou de reavivagem de pontas de projétil (Dias, 2003; Okumura; Araujo, 2014; Suárez, 2016).

No sítio Alfredo Henrique Wagner, as pontas de sílex, de arenito silicificado e de quartzo foram produzidas a partir de esquemas operatórios que não variam conforme o tipo de pedúnculo, já que este geralmente aparece nas etapas finais. Não percebemos uma preferência pela manufatura de determinada categoria conforme a matériaprima, apesar de termos encontrado um bom número de peças em arenito silicificado com o pedúnculo convexo.

Reforçando ainda a classificação dos tipos de pedúnculo, foram observadas 429 pontas de projétil que fazem parte da coleção do Museu de Arqueologia de Lomba Alta pertencentes a sítios localizados no município de Alfredo Wagner (Figura 3). Os resultados da análise indicam a utilização das mesmas matérias-primas, sendo o sílex a mais utilizada, seguido do quartzo e do arenito silicificado. Grande parte das pontas enquadra-se nas categorias criadas para o sítio Alfredo Henrique Wagner, demonstrando a semelhança presente nos instrumentos líticos da região.

As pontas de projétil em sílex do sítio Alfredo Henrique Wagner foram produzidas principalmente a partir da exploração inicial dos suportes por percussão bipolar, seguida do lascamento unipolar, enquanto os instrumentos em arenito silicificado e em quartzo 


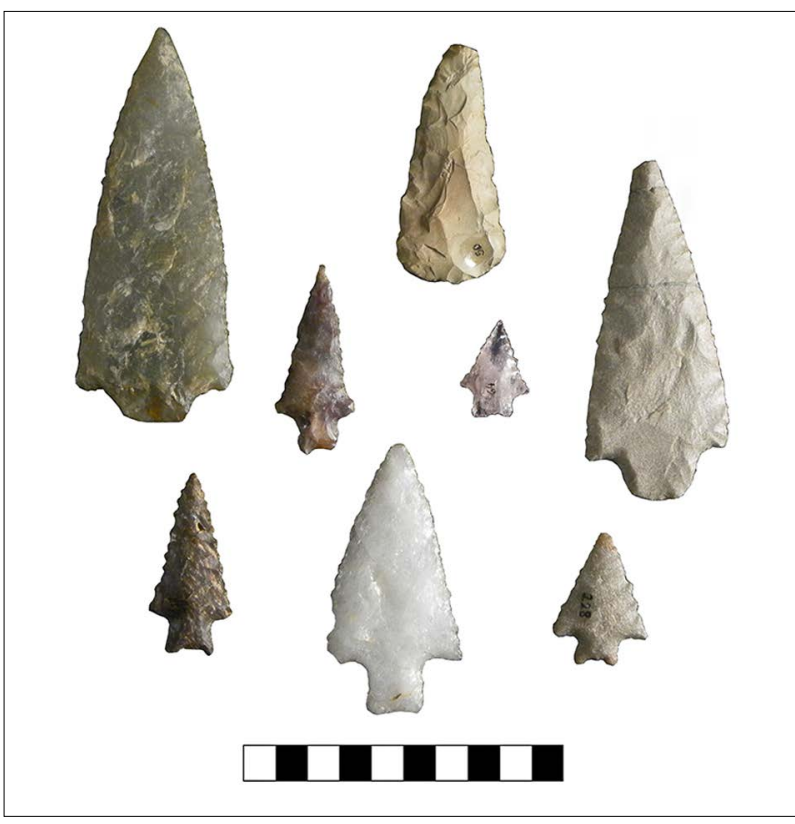

Figura 3. Pontas de projétil encontradas na região de Alfredo Wagner Fonte: Museu de Arqueologia de Lomba Alta. Fotos e montagem: Fernando de Almeida (2018).

leitoso foram produzidos unicamente por percussão unipolar. Estes podem ser caracterizados pela retirada de lascas com morfologias pré-determinadas, e por duas sequências operatórias, identificadas pelo lascamento inicial da face dorsal da lasca, seguido do lascamento bifacial. Em muitos casos, foi possível observar que o pedúnculo das pontas corresponde à parte proximal da lasca unipolar, independentemente do tipo dele. Já nas pontas da coleção do Museu de Arqueologia de Lomba Alta foi possível observar a utilização de lascas unipolares como suporte para a produção em algumas peças.

O sítio Chapadão Paulo Saturno, localizado em uma área de topo na bacia hidrográfica do rio Jararaca, afluente do rio Itajaí do Sul, diferencia-se dos demais pela magnitude da coleção, apresentando alta densidade de materiais arqueológicos, tanto em superfície quanto em subsuperfície. Outra configuração peculiar é a existência de material lítico em profundidade, embora em baixa densidade nos níveis mais profundos. Com relação às pontas, o que chama a atenção é o fato de haver vestígios possivelmente relacionados a diferentes etapas da cadeia operatória, indicando ser este um local de produção e de descarte de pontas de projétil.

Segundo Wagner (2002), nesse local haveria dois sítios arqueológicos (Lúcio da Silva e Arnoldo Leopoldo Silva), contudo, ao realizarmos caminhamentos sistemáticos no terreno, encontramos materiais líticos em uma área de aproximadamente $700 \mathrm{~m}^{2}$, verificando que se trata de um único sítio. A abertura de uma área de escavação com $2 \mathrm{~m}^{2}$ e $90 \mathrm{~cm}$ de profundidade proporcionou a identificação de material arqueológico até os $70 \mathrm{~cm}$ de profundidade, em concordância com o resultado das tradagens que evidenciaram material lítico à profundidade de até $1 \mathrm{~m}$. Essa atividade, somada à coleta de superfície realizada no sítio, gerou uma coleção de aproximadamente 2.000 vestígios arqueológicos.

Embora não tenhamos realizado intervenções, o sítio Alexandre foi visitado, e observou-se que lá foram coletadas pelos moradores dezenas de pontas de projétil durante as atividades agrícolas. $\bigcirc$ sítio localiza-se em um patamar de vertente, próximo à confluência dos rios Jararaca e Itajaí do Sul. No terreno, foi possível observar grande quantidade de lascas, principalmente produzidas a partir da exploração de quartzo leitoso e sílex. Os proprietários do terreno fizeram uma doação de dezenove pontas de projétil, as quais foram produzidas em quartzo leitoso e sílex e possuem características similares ao contexto evidenciado no sítio Alfredo Henrique Wagner.

Além da preferência por área de topo, não foi possível, ainda, perceber nenhuma correlação entre tamanho, implantação do sítio e composição artefatual.

Um ponto que merece menção diz respeito à caracterização de alguns destes sítios como 'mancha preta'. Ainda não foi possível identificar um padrão claro para essa caracterização, uma vez que há bastante variação com relação ao tamanho das áreas nas quais essas manchas aparecem, assim como diferenças com relação à intensidade da coloração, da composição artefatual e da área de implantação. Outro ponto diz respeito à intensidade da 
atuação agrícola, responsável por interferir de forma significativa nos sítios identificados nas décadas de 60 a 80 , os quais foram definidos pela presença destas marcas.

Outra variação entre os sítios, conforme mencionamos, diz respeito à composição dos vestígios líticos, que engloba, além das pontas de projétil, artefatos diversos, como os instrumentos bifaciais de grande porte, unifaciais e polidos, lascas retocadas, bem como inúmeros resíduos de lascamento associados à produção desses instrumentos, como lascas, núcleos e detritos. Há sítios onde está presente praticamente toda essa diversidade de vestígios, assim como há aqueles nos quais encontramos apenas parte deste repertório.

Estariam estes sítios associados sincronicamente ou seriam eles resultados da diacronia no processo de ocupação da área?

\section{OS ABRIGOS SOB ROCHAS}

Os abrigos sob rochas que existem em Alfredo Wagner fazem parte da formação que constitui a sequência da bacia do Paraná, preenchida por rochas sedimentares e vulcânicas (Schröder, 2005). Eles foram formados a partir de processos erosivos, causados por diferentes fatores, e entre eles destacam-se a erosão mecânica pela ação da água corrente, a erosão diferencial, que atinge camadas litológicas de diferentes naturezas, as diaclases, causadas por movimentos tectônicos, e o desmoronamento (Schröder, 2005).

Os abrigos sob rochas identificados no município aparecem em bom número nos paredões rochosos localizados nas áreas de encosta, próximos aos vales do rio Itajaí do Sul, bem como de seus principais afluentes. Além disso, aparecem também em áreas mais elevadas, embora em menor quantidade.

Os trabalhos desenvolvidos pela equipe do LEIA em abrigos sob rochas em Alfredo Wagner envolveram a realização de prospecção interventiva através de tradagens. Ao todo, foram visitados e/ou prospectados nove abrigos sob rochas. A maioria não possuía sedimentação, o que impediu a execução de tradagens (Águas Negras, Argentino, Lauro Mariotti). Nos casos onde essa atividade foi possível, o trado alcançava no máximo $40 \mathrm{~cm}$ de profundidade (Riozinho, Indiozinho, São Leonardo). Somente nos abrigos Catuíra, SC-VI-33 - Alto Jararaca II e SC-VI-15 - Lomba Alta foi possível obter mais dados sobre a estratificação, apesar de não terem sido encontrados vestígios arqueológicos.

O abrigo Catuíra, de formação arenítica, localizase no distrito de Catuíra, no município de Alfredo Wagner. Ao longo da atividade, encontramos inúmeros blocos de arenito de pequeno, médio e grande porte em subsuperfície (todos sem sinais de modificação), presentes em toda a estratificação e em todas as tradagens. A presença dessas rochas foi frequente em algumas áreas do abrigo, sendo a escavação encerrada logo nos primeiros níveis estratigráficos. Alcançamos uma grande profundidade somente em uma das tradagens - cerca de $80 \mathrm{~cm}$-, verificando a existência de grande número de blocos rochosos de arenito e de um sedimento arenoso acinzentado em toda a estratificação.

O abrigo SC-VI-33 - Alto Jararaca II é de formação arenítica e se localiza na comunidade de Alto Jararaca, em Alfredo Wagner. Ele é composto por vegetação rasteira, com bastante sedimentação e piso levemente inclinado, sendo que algumas dessas características possibilitariam a identificação de vestígios arqueológicos enterrados. Em grande parte das tradagens realizadas, identificamos um sedimento húmico areno-argiloso nas camadas iniciais, contendo raízes; e no restante da estratificação, que alcançava até $80 \mathrm{~cm}$ em alguns pontos, era comum o aparecimento de blocos de arenito de pequeno e médio porte, provenientes do paredão rochoso ao fundo do abrigo. O abrigo sob rochas SC-VI-15 - Lomba Alta localizase na comunidade de Poço Certo, em Lomba Alta, no município de Alfredo Wagner. O terreno no local foi parcialmente aterrado e planificado para a implementação de um oratório. Moradores locais afirmam que já foram encontrados vestígios arqueológicos nesse abrigo, porém, 
devido à facilidade do acesso e da frequente visitação, bem como de seu uso para a celebração de missas, acredita-se que muitos vestígios já foram retirados do local. Nesse abrigo, foram planejadas 17 tradagens, entre as quais a grande maioria não ultrapassou os $10 \mathrm{~cm}$ de profundidade, devido à grande quantidade de rochas na estratificação. Contudo, em uma das tradagens, na porção mais preservada do abrigo, onde não houve aterramento, foi encontrado um fragmento cerâmico, que, apesar de diminuto, apresenta características da Tradição Taquara/Itararé.

Com relação aos remanescentes ósseos humanos do sítio em abrigo SC-VI-33 - Alto Jararaca II, De Masi (2001) coletou amostras para análise de isótopos de carbono (13/12C) e de nitrogênio (15/14N), bem como para datação. Como resultado do estudo isotópico, o pesquisador percebeu que a dieta do indivíduo analisado condiz com o esperado para caçadores-coletores do interior, ou seja, é predominantemente baseada em recursos terrestres e não apresenta indícios de adoção de alimentos cultivados.

Os vestígios ósseos humanos do sítio SC-VI-33 - Alto Jararaca II também foram analisados por Scherer (2015) sendo que, através da análise do número mínimo de indivíduos, ela identificou a presença de cinco indivíduos, sendo três adultos (um do sexo masculino e dois do sexo feminino, possivelmente) e duas crianças.

\section{AS ESTRUTURAS SUBTERRÂNEAS}

Em geral, os sítios compostos por estruturas subterrâneas localizados no Alto Vale do Itajaí do Sul estão localizados entre as cotas de 400 e 1.200 m de altitude, porém há maior recorrência entre 800 e 1.000 m. Reis (2015) percebeu dois padrões de implantação dos sítios de estruturas subterrâneas, conforme o relevo local.
O primeiro diz respeito aos sítios localizados em cadeias de morros, próximos às nascentes e aos cursos de água menores, ou seja, nos divisores de águas das microbacias hidrográficas. O segundo remete às estruturas subterrâneas situadas em patamares nas imediações da escarpa do vale dos grandes rios. Os dois padrões estão relacionados à ocupação da porção alta do município, tanto nos morros quanto em patamares.

A partir dos dados reunidos na literatura arqueológica (Rohr, 1971, 1984; Wagner, 2002) e das informações coletadas em campo (Reis, 2015; Reis et al., 2018), percebemos a existência de, pelo menos, 45 registros de sítios compostos por estruturas subterrâneas em Alfredo Wagner, sendo que no total somam 252 depressões arqueológicas. Os referidos contextos arqueológicos têm a seguinte variação de concavidades por sítio: 1, 2, 3, 4, 5, 6, $8,10,15,18$ e 45. Assim, considerando o que se sabe até então, percebemos que há predomínio de sítios contendo uma a três unidades (45\%) e quatro a oito (36\%).

Em quatro sítios registrados por Wagner (2002) também constam informações sobre a existência de um aterro associado às estruturas subterrâneas, sendo que esses sítios possuem 1, 4, 7 e 45 concavidades arqueológicas, sendo todos localizados em cadeias de morros.

Entre 2014 e 2015, a equipe do LEIA realizou escavações em um sítio dessa categoria: sítio Tobias Wagner, localizado em um patamar de vertente, a cerca de $100 \mathrm{~m}$ da escarpa do vale do Arroio Lomba Alta, e em uma altitude média de 767 m em relação ao nível do mar. Ele é composto por 18 estruturas subterrâneas aparentemente dispostas em um padrão circular ou elíptico no entorno do patamar da vertente em que se localizam -, além de apresentar feições e ocorrências esparsas em superfície. Os vestígios estão dispersos em uma área de,

6 Conforme identificação feita por Scherer (2015, p. 306), a coleção é composta por: "[...] 02 fêmures direitos quebrados; 03 tíbias direitas quebradas; 04 tíbias esquerdas quebradas (uma delas infantil); 01 talus direito; 4 metatarsal direito; 02 ossos do quadril direito quebrados (ílio e ísquio); 01 ílio direito quebrado; 03 ilíacos esquerdos quebrados; 03 úmeros direitos quebrados; 03 úmeros esquerdos quebrados; 01 rádio esquerdo quebrado; 02 escápulas direitas quebradas; 02 escápulas esquerdas quebradas; 08 fragmentos de costelas; 01 vértebra torácica; 02 fragmentos de crânio; 01 mandíbula quebrada (recém-nascido); 19 fragmentos de ossos longos; 07 fragmentos ósseos diversos".

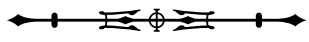


aproximadamente, $2.000 \mathrm{~m}^{2}$. Parte do sítio é encoberta por Mata Atlântica, sob o restante há plantação de Pinus elliottii Engelm.

Três estruturas subterrâneas e uma feição em superfície (denominada de área 1) sofreram intervenções, totalizando 10,25 $\mathrm{m}^{2}$ de área escavada do plano superficial. Através das escavações, identificamos oito camadas estratigráficas de solo que formam o sítio.
Foram coletados vestígios arqueológicos em sete delas. Em geral, os materiais encontrados consistem em vestígios arqueobotânicos (carvão, semente e nó de pinho), líticos (lascados, polidos e picoteados) e fragmentos cerâmicos da Tradição Taquara/Itararé (Figura 4).

Duas amostras de carvão oriundas da área 1 foram identificadas pela espécie Araucaria angustifolia (Bertol.) Kuntze (pinheiro-do-paraná); outras duas, de mesma

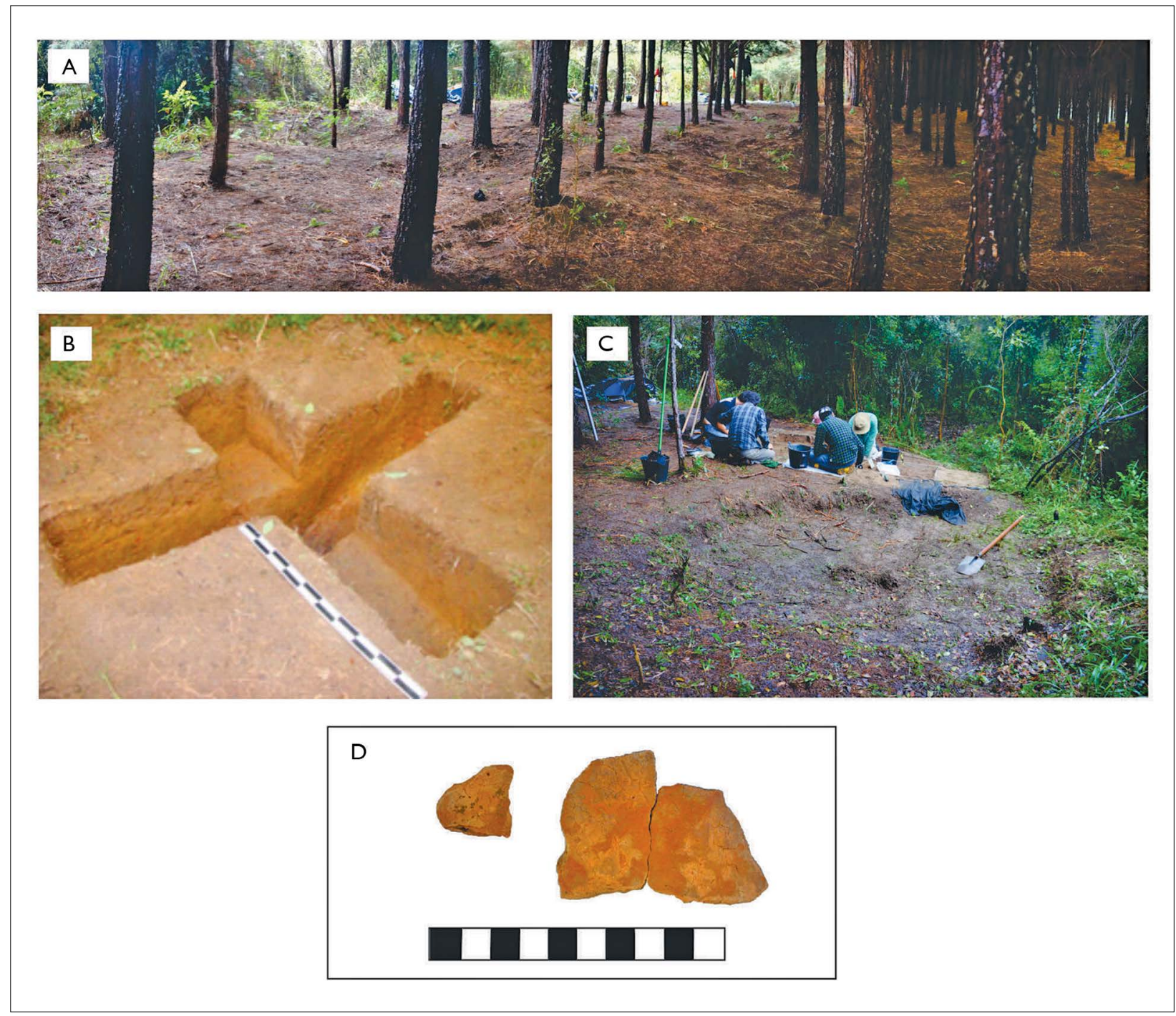

Figura 4. Prancha de fotos do sítio arqueológico Tobias Wagner: A) visão geral do sítio Tobias Wagner; B) estrutura subterrânea (E01) após escavação; C) escavação sendo realizada na área 1 - E01 em primeiro plano; D) exemplos de vestígios cerâmicos coletados na estrutura subterrânea (fragmento de borda à esquerda e fragmentos de parede remontados à direita). Fotos: acervo do LEIA/UFSC. Fotos registradas em 2013 e 2014. Prancha elaborada por Lucas Bond Reis (2018).

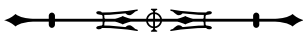


proveniência, foram identificadas pelo gênero Magnolia, sendo que, possivelmente, se trata da espécie Magnolia ovata (A. St.-Hil.) Spreng. (pinha-do-brejo ou baguaçu). Informações etnohistóricas e etnográficas atestam a utilização destas espécies por grupos Jê meridionais (Reis, 2015).

\section{OS SÍTIOS COM MONTÍCULOS}

Há apenas um registro de sítio composto exclusivamente por montículos no Alto Vale do Itajaí do Sul. São, portanto, escassos os detalhes acerca desse tipo de contexto na área, não sendo conhecidos elementos suficientes para se perceber padrões acerca de composição, implantação etc.

Segundo Rohr (1967), o sítio é composto por nove montículos, divididos em dois grupos: o primeiro com sete e o segundo com dois. $\bigcirc$ primeiro conjunto está localizado em um pasto, "[...] encostados em uma lomba suave [...]” (Rohr, 1967, p. 23), sendo que cinco montículos estão alinhados no sentido da vertente, apresentando $6 \mathrm{~m}$ de diferença máxima de altitude, e dois montículos estão mais deslocados. Os montículos do segundo conjunto estão localizados em uma roça. Rohr (1967) realizou intervenções em um deles, com formato circular ( $3 \mathrm{~m}$ de diâmetro e 0,5 $\mathrm{m}$ de altura), onde coletou um pequeno recipiente de barro não cozido que "[...] possuía trinta centímetros de diâmetro e continha terra poeirenta solta [...]" (Rohr, 1967, p. 23), além de fragmentos de carvão.

Em reconhecimento em campo, a equipe do LEIA (Reis et al., 2018) percebeu que a área onde se encontra o sítio Demora foi intensamente lavrada ao longo dos últimos 50 anos $^{7}$. Os atuais proprietários têm conhecimento acerca da pesquisa realizada anteriormente, bem como sobre a existência dos referidos montículos. Contudo, nenhum dos amontoados de terra sobreviveu ao arado e ao plantio, da mesma forma como nenhum dos atuais proprietários relatou ter encontrado artefatos. O sítio estaria localizado em média vertente, em área pouco inclinada.

Conforme salientado anteriormente, Wagner (2002) menciona a existência de quatro sítios de estruturas subterrâneas em que há também um aterro. Porém, não apresenta detalhes acerca da morfologia dos aterros, da composição e da implantação. Sabe-se apenas que se localizam junto a sítios de estruturas subterrâneas, localizados em áreas de morros.

\section{CRONOLOGIA}

A partir de amostras provenientes dos contextos mencionados, são conhecidos pelo menos três referenciais cronológicos acerca da ocupação pré-colonial da área do município.

A primeira amostra, indicada no Quadro 2, é oriunda da camada mais recente do sítio SC-VI-13. Em uma síntese acerca do contexto arqueológico em Santa Catarina, Prous e Piazza (1977) publicaram a informação acerca de uma datação, a partir de amostra coletada por Walter Piazza para a camada superior do sítio em 3.000 AP, sem mais detalhes sobre a proveniência da amostra e/ou se é calibrada. Rohr (1984) acrescentou que a datação foi efetuada pelo Museu Nacional de Washington.

A segunda foi obtida por De Masi (2001, p. 81), a partir de uma amostra denominada "ALFREDO WAGNER (Alto Jararaca)", possivelmente oriunda da coleção SCVI-33 - Alto Jararaca II, sob guarda do MArquE/UFSC.

A terceira consiste em uma amostra coletada pela equipe do LEIA/UFSC no sítio Tobias Wagner, proveniente de uma estrutura de combustão, localizada na área externa às estruturas subterrâneas (Reis, 2015).

Ampliando a busca por informações cronológicas para compreender melhor o processo de ocupação do Alto Vale do Itajaí do Sul, compilamos, no Quadro 3, outras dez datas obtidas por meio de amostras coletadas no Alto Vale do Itajaí como um todo.

\footnotetext{
Desde a pesquisa efetuada por Rohr (1967).
}

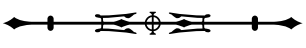


Quadro 2. Datações de sítios arqueológicos em Alfredo Wagner. Legenda: * = calibrada.

\begin{tabular}{|c|c|c|c|c|}
\hline Sítio & Tipo & Data & Amostra/Laboratório & Referências \\
\hline SC-VI-13 & Céu aberto & $\begin{array}{c}3.000 \mathrm{AP} \\
\text { (amostra desconhecida) }\end{array}$ & Museu Nacional de Washington & $\begin{array}{c}\text { Prous e Piazza (1977); } \\
\text { Rohr (1984) }\end{array}$ \\
\hline Alto Jararaca II & Abrigo sob rochas & $\begin{array}{c}1.610 \mathrm{AP} * \\
\text { (colágeno) }\end{array}$ & $\begin{array}{c}53916 / \text { Lawrence Livermore National } \\
\text { Laboratory Center }\end{array}$ & De Masi (2001) \\
\hline Tobias Wagner & $\begin{array}{c}\text { Estruturas } \\
\text { subterrâneas }\end{array}$ & $300 \pm 30 \mathrm{AP}$ (carvão) & Beta-410430 & Reis (2015) \\
\hline
\end{tabular}

Quadro 3. Datações de sítios arqueológicos localizados no Alto Vale do Itajaí.

\begin{tabular}{|c|c|c|c|c|c|}
\hline Sítio & Tipo & Município & Data (AP) & Laboratório & Referência \\
\hline SC-TA-19 & Lítico a céu aberto & Taió & $\begin{array}{c}8.090 \pm 50 \\
\text { (carvão; AMS) }\end{array}$ & Beta 233601 & Schmitz et al. (2009) \\
\hline SC-TA-19 & Lítico a céu aberto & Taió & $\begin{array}{l}7.880 \pm 60 \\
\quad(\text { carvão) }\end{array}$ & Beta 256217 & Schmitz et al. (2009) \\
\hline SC-TA-03 & Lítico a céu aberto & Taió & $\begin{array}{l}4.140 \pm 60 \\
\quad \text { (carvão) }\end{array}$ & Beta 228164 & Schmitz et al. (2009) \\
\hline SC-TA-03 & Lítico a céu aberto & Taió & $\begin{array}{l}4.110 \pm 40 \\
\text { (carvão) }\end{array}$ & Beta 229857 & Schmitz et al. (2009) \\
\hline Operário & Lítico a céu aberto & Ibirama & $\begin{array}{c}4.080 \pm 40 \\
\text { (carvão; AMS) }\end{array}$ & Beta 326083 & $\begin{array}{c}\text { Consciência Consultoria } \\
\text { Científica (2014) }\end{array}$ \\
\hline SC-TA-04 & Estruturas subterrâneas & Taió & $\begin{array}{c}1.390 \pm 50 \\
\text { (carvão) }\end{array}$ & Beta 247953 & Schmitz et al. (2009) \\
\hline $\begin{array}{c}\text { SC-VI-16 } \\
\text { (Ribeirão da Herta) }\end{array}$ & Abrigo sob rochas & $\begin{array}{l}\text { Presidente } \\
\text { Getúlio }\end{array}$ & $\begin{array}{c}1.290 \\
\text { (colágeno; calibrada) }\end{array}$ & CAMS 53114 & De Masi (2001) \\
\hline SC-TA-04 & Estruturas subterrâneas & Taió & $\begin{array}{c}1.220 \pm 50 \\
\text { (carvão) }\end{array}$ & Beta 228165 & Schmitz et al. (2009) \\
\hline SC-TA-04 & Estruturas subterrâneas & Taió & $\begin{array}{l}1.180 \pm 40 \\
\quad \text { (carvão) }\end{array}$ & Beta 229856 & Schmitz et al. (2009) \\
\hline SC-TA-04 & Estruturas subterrâneas & Taió & $\begin{array}{c}650 \pm 50 \\
\text { (carvão) }\end{array}$ & Beta 214107 & Schmitz et al. (2009) \\
\hline $\begin{array}{c}\text { SC-VI-10 } \\
\text { (Rio Krauel) }\end{array}$ & Lítico a céu aberto & Ibirama & $\begin{array}{c}660 \pm 80 \\
\text { (carvão) }\end{array}$ & SI 537 & Machado (2016) \\
\hline $\begin{array}{l}\text { SC-VI-10 } \\
\text { (Rio Krauel) }\end{array}$ & Lítico a céu aberto & Ibirama & $\begin{array}{c}290 \pm 80 \\
\text { (carvão) }\end{array}$ & SI 536 & Machado (2016) \\
\hline
\end{tabular}

\section{DISCUSSÃO}

\section{SÍTIOS LÍTICOS, PONTAS DE PROJÉTIL E A TRADIÇÃO UMBU}

Existem, atualmente, poucos dados sobre a Tradição Umbu no Alto Vale do Itajaí. As pesquisas arqueológicas no interior de Santa Catarina intensificaram-se entre a década de 60 e o início da década de 80 (Noelli, 1999-2000), sendo que, nesse período, foram identificadas diversas fases précerâmicas vinculadas à Tradição Umbu - posteriormente descartadas devido a diferentes fatores, como a ausência de descrições e de definições formais em publicações ou, ainda, a presença de sítios sem associação com pontas de projétil (Dias, 1994). Esse é o caso da fase Urubici, datada 
em $910 \pm 200$ (SI 227), que englobava quatro abrigos com petróglifos ${ }^{8}$, sem, no entanto, associação com pontas de projétil, assim como a fase Itajaí, cuja definição não foi formalizada por Walter Piazza (Dias, 1994).

As fases arqueológicas restantes (Suruvi e Itaió) também apresentam problemas contextuais e não oferecem parâmetros suficientes para que possamos incluí-las no debate sobre os sítios da Tradição Umbu. A fase Itaió, por exemplo, foi definida a partir da identificação de abrigos sob rocha e de sítios a céu aberto em uma área muito ampla, de mais de 15.000 km², no planalto de Canoinhas, no norte de Santa Catarina (Piazza, 1974). O contexto cronológico definido para essa fase baseia-se em duas datações obtidas em outra área, a partir de amostras do sítio SC-VI-10: Krauel, localizado em Presidente Getúlio, no Alto Vale do Itajaí, e que aparentemente não possui relação alguma com a fase Itaió.

Já a fase Suruvi caracteriza-se por ser pré-cerâmica e, conforme Piazza (1971), teria precedido à Tradição Tupiguarani, sendo definida a partir da identificação de dois sítios próximos ao rio Uruguai, na divisa com o estado do Rio Grande do Sul, onde foram encontradas pontas de projétil com pedúnculo e aletas, bem como pontas apedunculadas e pontas foliáceas retocadas, produzidas em arenito, quartzo leitoso, ametista e calcedônia (Piazza, 1971). Contudo, assim como outros sítios líticos identificados ao longo do rio Uruguai durante o Programa Nacional de Pesquisas Arqueológicas (PRONAPA), os dados apresentados por Piazza (1971) indicam a possibilidade da existência de uma relação contextual entre esses sítios e os sítios cerâmicos encontrados na mesma área (Dias; Jacobus, 2003).

Sendo assim, de maneira geral, as informações mais confiáveis sobre a Tradição Umbu derivam de projetos de pesquisa posteriores ao PRONAPA, que procuram compreender esses sítios líticos a partir de enfoques regionais e/ou de trabalhos orientados ao estudo tecnológico das indústrias líticas, cujo foco não é a compreensão dos aspectos morfológicos dos materiais (Dias, 1994, 2003; Hoeltz, 2005; Hoeltz et al., 2015).

Para o Holoceno Inicial e Médio, em Santa Catarina, estes sítios estão localizados no oeste do estado e no Alto Vale do Itajá (Lourdeau et al., 2014; Schmitz et al., 2009). No Alto Vale do Itajaí do Oeste, nos municípios de Taió e Mirim Doce, foram estudados 26 sítios a céu aberto com pontas de projétil (Schmitz et al., 2009). No ponto Pia 02, do sítio SC-TA-03, em Taió, a equipe do Instituto Anchietano obteve duas datações - 4.110 \pm 60 C14 AP e $4.140 \pm 40$ C14 AP (Schmitz et al., 2009, p. 205-206) -, enquanto no sítio SC-TA-19 foram obtidas datações de $8.090 \pm 50$ C14 AP e $7.880 \pm 60$ C14 AP (Schmitz et al., 2009, p. 223-226). Em ambos os sítios, foram encontradas pontas de projétil nos níveis datados.

Conforme publicação sobre a pesquisa realizada nessa região (Schmitz et al., 2009), os materiais líticos analisados demonstram a utilização de matérias-primas de origem local, sendo o sílex a preferencial, utilizada principalmente para a produção das pontas de projétil. As escavações realizadas indicam que os instrumentos foram produzidos e utilizados nos próprios sítios, não se tratando de locais de atividades específicas. Em alguns casos, foram encontradas, em associação com os instrumentos líticos, as estruturas de fogueiras, isoladas ou agrupadas. Além disso, os sítios identificados na região são numerosos em áreas mais altas, aparecendo em menor quantidade à medida que se aproximam do vale.

No oeste de Santa Catarina, em pesquisas realizadas no canteiro de obras da usina hidrelétrica (UHE) Foz do Chapecó, foram identificados três sítios arqueológicos (Linha Policial 1, Linha Policial 2 e Alto Alegre 3), com datas entre $8.370 \pm 60$ C14 AP e $8.270 \pm 70$ C14 AP (Dias; Hoeltz, 2010, p. 56; Lourdeau et al., 2014, p. 191-192; Hoeltz et al., 2015, p. 3-6). Posteriormente, a

8 Riris e Corteletti (2015) e Corteletti (2012) acreditam que, possivelmente, as representações rupestres são de autoria de grupos Jê meridionais.

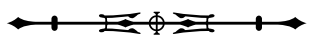


partir dos resultados dessas pesquisas, novas escavações foram realizadas no sítio arqueológico Linha Policial 7 , cujo conjunto arqueológico inferior possui datações entre $9.925 \pm 45$ C14 AP e $9.865 \pm 50$ C14 AP (Lourdeau et al., 2016, p. 227). No conjunto arqueológico principal, foram realizadas cinco datações, três delas indicando datas entre $8.585 \pm 40$ C14 AP e $8.905 \pm 40$ C14 AP, e uma quarta data de C14 $9.450 \pm 45$ (Lourdeau et al., 2016, p. 229). Em outro setor do mesmo sítio, pequenos grãos de carvão foram encontrados e dois deles foram datados, produzindo datas de $395 \pm 30$ C14 AP e $7.160 \pm 40$ C14 AP.

Nesses sítios, foram identificados distintos esquemas operatórios de produção de instrumentos líticos. Porém, destaca-se a debitagem laminar, raramente descrita na pré-história americana e, até então, desconhecida em contextos brasileiros (Lourdeau et al., 2014). Tal produção é feita por percussão interna e marginal, utilizando-se um método único, que é a inicialização centrípeta da superfície de lascamento e a produção unidirecional de lâminas (Lourdeau et al., 2014, 2016; Hoeltz et al., 2015). Essas lâminas serviram de suportes de instrumentos variados. O predomínio está na presença de "[...] gumes laterais e agudos [...], retocados ou não", enquanto "[...] as partes transformativas distais são relativamente raras" (Hoeltz et al., 2015, p. 16), mas existem.

Uma situação particular ocorre nesses sítios, em que não é possível atribuir uma associação cultural para a ocupação dos níveis mais profundos, pois esse sistema tecnológico era até então desconhecido no país (Lourdeau et al., 2014). A presença de lâminas nunca foi considerada um critério para a inserção dos sítios na Tradição Umbu, e nenhum sítio atribuído a essa tradição possui evidências sobre essa produção em publicações científicas (Lourdeau et al., 2014). Tal conclusão permite problematizar os trabalhos cujo foco recai exclusivamente sobre a produção de pontas de projétil, bem como insere novos elementos, a partir da tecnologia lítica, fundamentais para $\mathrm{o}$ melhor entendimento sobre a variabilidade tecnológica das indústrias líticas da Tradição Umbu.
Para além desses contextos associados ao Holoceno Inicial e Médio, há sítios arqueológicos localizados na encosta da serra catarinense e também caracterizados pela presença de pontas de projétil, para os quais foram obtidas três datações recentes: 290 AP \pm 80 C14 AP e $660 \pm 80$ C14 AP, para o sítio SC-VI-10 - Rio Krauel, localizado em Presidente Getúlio, no Alto Vale do Itajaí (Machado, 2016), e $230 \pm 60$ C14 AP, para o sítio SC-MG-01, localizado em Major Gercino, na encosta de Santa Catarina (Farias, 2005).

Até o momento, não foi possível obter datações absolutas para os sítios arqueológicos com presença de pontas de projétil localizados na área de pesquisa. Sendo assim, as informações disponíveis até então referem-se principalmente às características tecnológicas das indústrias líticas de sítios do Alto Vale do Itajaí, as quais necessitam ser comparadas com contextos datados na mesma região.

A análise preliminar do material arqueológico encontrado em Alfredo Wagner aponta para o uso predominante de sílex, seguido pelo quartzo e pelo arenito silicificado. Para a produção das pontas, identificamos sequências que envolvem a articulação de lascamento bi e unipolar, assim como sequências exclusivamente unipolares. Há uma variação morfológica, tanto no que se refere à forma geral quanto especificamente ao pedúnculo, mas ainda não foi possível perceber uma associação entre este aspecto, a técnica de produção e a matéria-prima. Conforme já mencionamos, nem todos os sítios da área apresentam pontas de projétil, sendo frequente a presença de outros vestígios líticos, tais como bifaces, instrumentos unifaciais, lascas retocadas, machados polidos, entre outros.

Há semelhanças entre as pontas bifaciais do Museu Arqueológico de Lomba Alta com o conjunto de pontas do sítio Alfredo Henrique Wagner, no que diz respeito ao suporte utilizado e à morfologia do pedúnculo. Durante a análise, tivemos a oportunidade de observar as mesmas categorias de pontas pedunculadas identificadas no Sítio Alfredo Henrique Wagner, que inclui os três tipos de pontas com pedúnculos bifurcado, reto e convexo, e as pontas apedunculadas. Por outro lado, o corpo - 
parte localizada entre a parte superior do pedúnculo e o ápice das pontas bifaciais - pode divergir, apresentando diferentes morfologias e tamanhos, destacando-se algumas pontas que alcançam até $12 \mathrm{~cm}$ de comprimento, algo que não vimos no sítio Alfredo Henrique Wagner.

Se, por um lado, notamos que há certa variabilidade entre os sítios no que se refere à implantação (compartimento da paisagem), ao tamanho, à densidade e à composição, por outro não dispomos de dados mais circunstanciados que nos permitam compreender a articulação (ou não conexão) entre eles. Com relação à composição, a diferença se dá principalmente no que concerne à presença/ausência de pontas de projétil, pois, a princípio, parece haver certa homogeneidade entre os sítios, no que diz respeito à variação morfológica, à diversidade de matérias-primas e às sequências operacionais envolvidas na produção das pontas de projétil.

Para complexificar este ponto, incorporando os referenciais cronológicos disponíveis para todo o Alto Vale do Itajaí, encontramos sítios com composição semelhante datados no Holoceno Inicial e no Holoceno Recente. Em relação aos sítios mais recentes, como o SC-VI-10 - Rio Krauel, foram encontradas quantidades significativas de pontas de projétil, enquanto nos sítios mais antigos, como os sítios SC-TA-19 e SC-TA-03, existem vestígios que apontam para a produção de pontas em unidades residenciais, compostas por estruturas de combustão e por artefatos líticos.

\section{A OCUPAÇÃO JÊ MERIDIONAL}

Pesquisas que problematizam a ocupação Jê meridional no planalto sul brasileiro através de diferentes perspectivas têm sido desenvolvidas desde a década de 1990, contudo alcançaram volume mais expressivo e maior abrangência a partir dos anos 2000 (Noelli, 1996, 1999, 2004; De Masi, 2006; Schmitz et al., 2002, 2009; Copé, 2006).

Os dados reunidos recentemente têm mostrado que há ocupação Jê meridional milenar no planalto sul- brasileiro. Povos desta matriz cultural têm ocupado esta área desde, pelo menos 91.700 a 1.800 AP (Parellada, 2005; Schmitz; Brochado, 1972), conjuntamente à dispersão das Matas de Araucárias. Descobriu-se que, ao longo da história, estes povos atravessaram diversas transformações culturais, especialmente por volta do ano 1.000 AP, quando parece ter ocorrido uma mudança acentuada na forma de ocupar a paisagem e na prática de sepultar os mortos, provavelmente ocasionada por contatos interétnicos (Corteletti, 2012; Souza et al., 2016).

Em Santa Catarina,

Os sítios estão localizados no planalto, na serra ou no litoral, sendo que têm sido identificados como relacionados aos grupos Jê meridionais através da presença de cerâmica Taquara/Itararé ou da composição por estruturas subterrâneas e/ ou montículos funerários. (Reis, 2015, p. 266).

Um melhor entendimento sobre o processo de povoamento Jê meridional deve considerar também as transformações paleoambientais, além das características do tipo de cerâmica e dos sítios arqueológicos. Estudos realizados por ecólogos na porção meridional do planalto brasileiro, visando compreender a dinâmica do fogo, da vegetação e do clima, a partir de amostras de carvão e de pólen (Behling et al., 2004), vêm mostrando que a expansão da floresta de araucárias a partir de núcleos pioneiros coincide com as áreas ocupadas por povos Jê em períodos mais remotos (Iriarte; Behling, 2007; Copé, 2012; Reis et al., 2014). Em publicação recente, Robinson et al. (2018) apresentam uma discussão detalhada acerca do tema, com novos dados cronológicos, polínicos, isotópicos etc.

Noelli e Souza (2017), a partir de dados arqueológicos, linguísticos e históricos, argumentam que grupos Jê meridionais que ocupavam o vale do Ribeira, no sudeste de São Paulo, teriam adentrado o território que atualmente compõe a região do Sul do Brasil, por meio do nordeste do

9 De Masi (2006) apresenta datas de 2860 a.C. e 790 a.C. para sítios cerâmicos no baixo rio Canoas, as quais pressupõem um recuo temporal muito grande para o que se sabe atualmente acerca do processo de ocupação Jê meridional.

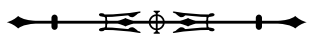


Paraná, ocupando os vales dos rios Itararé e Paranapanema. Adiante, considerando contatos interétnicos, sintetizam a expansão Jê subsequente da seguinte forma:

[...] os Guarani comprimiram os territórios Jê no alto Paranapanema e médio Iguaçu a aproximadamente 1.800 AP: 1) os expulsaram da beira-mar do Paraná ao Rio Grande do Sul a partir de 1.200 a 1 mil AP; 2) os comprimiram no alto rio Uruguai a aproximadamente 1.500 AP; 3) os empurraram para os campos de Caxias do Sul a cerca de 1.900 AP; 4) separaram os territórios dos vales do Ribeira e Tibagi e alto Iguaçu a cerca de 1.500 AP, criando dois núcleos Jê que persistiam no século XVII. (Noelli; Souza, 2017, p. 70).

Desse modo, baseando-se na proposta e no mapa de expansão apresentados por Noelli e Souza (2017), a ocupação Jê no que são atualmente solos catarinenses teria se iniciado de forma pioneira por meio da ocupação do litoral, bem como das terras altas e de suas adjacências no planalto norte. Assim, há uma expectativa de que, no Alto Vale do Itajaí como um todo, existam contextos com datas anteriores ao primeiro milênio da era cristã, além de sítios de ocupação mais recente, que resultam do processo subsequente de assentamento na área.

Contudo, foram desenvolvidas apenas três pesquisas arqueológicas sistemáticas que contemplam o estudo dessas ocupações em tal região: 1) em Taió (Schmitz et al., 2009); 2) na Terra Indígena Ibirama-Lã Klãno (Machado, 2016); e 3) em Alfredo Wagner (Reis, 2015). Considerando essas pesquisas e as informações cronológicas disponíveis (Quadro 3), percebe-se que as datas de $1.390 \pm 50$, de $1.220 \pm 50$ e de $1.180 \pm 40$ (todas C14 AP), registradas em estruturas subterrâneas pesquisadas em Taió, atestam o pioneirismo da ocupação do Alto Vale do Itajaí, sendo que o processo de ocupação dessa região teria sido iniciado por meio do povoamento do rio Itajaí do Oeste.

Devido aos baixos números de pesquisas na região e de amostras datadas, há uma carência de dados cronológicos que possibilite compreensão refinada do processo de ocupação Jê no Alto Vale do Itajaí. Apenas mais duas datações, ambas oriundas de contextos de estruturas subterrâneas, são conhecidas: $650 \pm 50$, em Taió, e $330 \pm$ 30, em Alfredo Wagner (ambas C14 AP). Essas informações sugerem que há ocupação contínua ou ao menos intermitente no rio Itajaí do Oeste, além da presença Jê no rio Itajaí do Sul em período anterior aos primeiros contatos com europeus que se tem registrado. Ademais, existe uma série de informações históricas e etnohistóricas produzidas a partir do século XVIII que atesta a presença de grupos Jê no Alto Vale do Itajaí como um todo até o presente (Santos, 1973; Reis, 2015).

Considerando o horizonte cronológico onde está situada a data obtida para o sítio Tobias Wagner, percebe-se que há ocupação contemporânea de contextos localizados em outros municípios catarinenses - Anita Garibaldi, Abdon Batista, São José do Cerrito, Urubici e Celso Ramos ${ }^{10}$. Assim, entre 400 e 260 AP, vê-se que

[...] os grupos Jê meridionais ocuparam uma área circunscrita do planalto catarinense, bem como as proximidades da Serra Geral Catarinense - um dos divisores de águas regionais -, já nas imediações da borda leste do planalto. (Reis, 2015, p. 268).

Diferentemente do contexto do planalto - onde há recorrência de datas oriundas de estruturas subterrâneas e/ou de montículos funerários -, apenas duas datas são conhecidas na borda leste do planalto/serra, sendo uma de um sítio cerâmico a céu aberto e a outra de um sítio composto por estruturas subterrâneas.

Considerando o diferente volume de pesquisas realizadas até então no planalto e na serra, Reis (2015, p. 269) propõe que "[...] os grupos Jê que se estabeleceram no Alto Vale do Itajaí podem ter desenvolvido uma dinâmica de ocupação territorial que implicava uma maior circulação nesse espaço [...]", as quais seriam “[...] motivadas por aspectos culturais e pelas especificidades do ambiente de transição entre litoral e planalto e entre a mata

\footnotetext{
10 Ver Tabela 15, Gráfico 45 e Figura 127 em Reis (2015, p. 294, 295, 296).
}

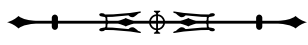


atlântica e a floresta de araucárias". Contudo, ressalta que tal diferenciação não deve ser relacionada a uma divisão entre grupos sedentários e/ou nômades, pois, em ambas as áreas, eles parecem ter estabelecido domínio territorial, sendo que os vestígios arqueológicos ${ }^{11}$ e as informações etnohistóricas atestam a longa duração destas ocupações. Assim, os grupos Jê teriam desenvolvido territorialidades específicas, no sentido proposto por Zedeño (2008) - uma soma de ações e emoções -, que resultaram em formas diferenciadas de ocupar o espaço nessas regiões distintas.

A partir do conhecimento que se tem atualmente acerca de tecnologia, de território e de cronologia em relação à ocupação Jê meridional no planalto em Santa Catarina, Reis (2015) sugeriu que essa área foi palco dos diferentes processos de história de formação territorial propostos por Zedeño (1997). Em síntese, inicialmente, parece ter ocorrido, entre 1.400 e 900 AP, um período de estabelecimento dos grupos Jê meridionais no planalto, associados à emergência dos núcleos pioneiros da Mata de Araucárias. A colonização da área ocorre também nesse período, com profusão de sítios com estruturas subterrâneas, seguida pelo assentamento, quando há recorrência de estruturas subterrâneas contemporâneas e/ou reocupadas em que aparecem vestígios cerâmicos. Por volta do ano 1.000 AP, ocorre um processo de expansão de grupos no sentido baixo/médio rio Canoas, concomitantemente à consolidação do assentamento no planalto. Neste contexto, sítios de arquitetura monumental ${ }^{12}$ passaram a ser construídos nas áreas altas do planalto. Ademais, considerando-se que a partir do ano 1.000 AP ocorre uma rápida expansão das Matas de Araucárias sobre as áreas de campos no planalto, bem como as informações etnohistóricas sobre o faccionalismo de grupos Kaingang, vislumbramos a ocorrência de um processo de fragmentação política do núcleo de ocupação pioneira. Como resultado desta fragmentação, outros sítios de arquitetura monumental passaram a ser construídos enquanto marcadores territoriais, e áreas mais distantes passaram a ser colonizadas, caso, por exemplo, do Vale do Itajaí e do oeste catarinense.

Deve-se considerar que o processo de expansão proposto por Reis (2015) considera tanto transformações ocasionadas por mudanças internas quanto resultantes de contatos com outros grupos culturais.

Conforme tem sido discutido por pesquisadores do tema (Noelli, 1999-2000, 2004; Souza et al., 2016; Noelli; Souza, 2017), o processo de migração Jê meridional é pautado, em muitas situações, pela relação que esses grupos estabeleceram com os Guarani. Desse modo, com base nos dados apresentados por Bonomo et al. (2015) acerca do processo de expansão Guarani na bacia do Prata e no litoral sul brasileiro, percebe-se que a área do planalto catarinense ocupada por grupos Jê encontra-se circunscrita pela presença Guarani pelo menos a partir do ano 1.000 AP. Ademais, também deve-se vislumbrar possíveis contatos com grupos caçadores-coletores que provavelmente ocupavam essas mesmas áreas há milênios (Dias, 2003) e, especialmente, para o Vale do Itajaí, também com grupos caçadores-pescadores-coletores que ocupavam o litoral ${ }^{13}$.

\footnotetext{
11 Corteletti (2012) identificou a presença de milho (Zea mays L.), mandioca (Manihot sp.), feijão (Phaseolus sp.), abóbora (Cucurbita sp.) e inhame (Dioscorea sp.) em amostras de grãos de amido e em fitólitos extraídos de fragmentos cerâmicos encontrados no sítio Bonin, em Urubici, Santa Catarina. De Masi (2006), a partir de análises de isótopos estáveis de carbono presentes em amostras coletadas em fragmentos cerâmicos, identificou a presença de vestígios de milho e de legumes em contexto de estruturas subterrâneas. Estas informações advogam no sentido de que, além da caça, da coleta e da pesca, os grupos Jê meridionais também praticavam a horticultura. Ademais, ainda que exista maior concentração de sementes maduras de pinhão no outono e no inverno, há disponibilidade destas ao longo de 11 meses, considerando-se a produção das diversas variedades de araucárias já identificadas (Corteletti, 2012). Além disso, Souza et al. (2016) noticiaram a identificação de doze camadas de ocupação de uma grande estrutura subterrânea (com 16 m de diâmetro) no sítio Baggio I, em Campo Belo do Sul, Santa Catarina, sendo que a concavidade foi ocupada de forma ininterrupta por mais de dois séculos.

12 Monticulares e/ou grandes estruturas escavadas, conforme Souza et al. (2016).

13 Conforme informações cronológicas apresentadas por Oppitz (2011).
}

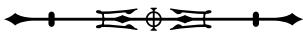


Especificamente no que diz respeito ao sítio Tobias Wagner, localizado no Alto Vale do Itajaí do Sul e único composto por estruturas subterrâneas já escavado na área, a partir dos dados reunidos, das análises tecnológicas efetuadas dos vestígios líticos e cerâmicos, bem como considerando a estratigrafia evidenciada, Reis (2015) sugere que uma das estruturas subterrâneas (E01 - objeto de um volume maior de escavações) consista em espaço de uso doméstico, possivelmente ocupado mais de uma vez; enquanto que a área 1, onde foi identificada uma estrutura de combustão, consista em espaço de acúmulo e de queima de resíduos.

Ademais, devido ao aparente padrão circular de disposição das estruturas subterrâneas no entorno de um patamar de vertente, identificado no sítio Tobias Wagner, Reis (2015) sugere a existência de um planejamento, ainda que diacrônico, no que diz respeito à construção das concavidades e do uso do espaço. Tal questão poderia estar relacionada a aspectos funcionais e/ou simbólicos preconizados pelo grupo que ali habitou preteritamente. Além disso, devido ao tangenciamento de algumas estruturas subterrâneas, Reis (2015) vislumbra a existência de ambientes domésticos compartimentados que foram ocupados sincronicamente, tal como observado por Corteletti (2012).

Considerando os vestígios líticos e cerâmicos encontrados no sítio Tobias Wagner, Reis (2015) aventa a possibilidade da existência de outros locais ocupados pelos grupos que utilizaram estas estruturas subterrâneas a fim de desenvolver atividades específicas, tais como busca de matéria-prima, produção de artefatos, áreas de plantio e de caça. Estes locais estariam matizados na paisagem sob a forma de sítios a céu aberto.

A partir de informações bibliográficas que indicam a utilização de abrigos sob rochas para a prática de sepultamentos humanos por grupos Jê meridionais (Beber, 2004; Corteletti, 2012), e considerando a existência de um abrigo, denominado de SC-VI-15 - Lomba Alta , nas proximidades do sítio Tobias Wagner, onde outrora foram encontrados remanescentes ósseos humanos (Wagner,
2002; Reis, 2015) e onde coletamos um fragmento de cerâmica Itararé, sugerimos que os grupos Jê meridionais que ocuparam o Alto Vale do Itajaí do Sul sepultavam seus mortos em abrigos sob rochas e possivelmente ocuparam abrigos localizados na área de pesquisa.

\section{PERSPECTIVAS}

De acordo com os dados apresentados e dialogando com um contexto mais amplo que abarca todo o Alto Vale do Itajaí do Sul, podemos vislumbrar ao menos três períodos de ocupação para a área de pesquisa:

1) Holoceno Inicial: o principal referencial cronológico para este período é o sítio SC-TA-19, localizado em Taió. As datas obtidas para este sítio colocam a região do Alto Vale do Itajaí para dialogar com outras áreas do Sul do Brasil, como oeste catarinense e noroeste do Rio Grande do Sul. No caso do Alto Vale do Itajaí do Sul, a ocupação associada a este período estaria representada por sítios líticos localizados nos topos de morros, nos quais pontas de projétil líticas aparecem com frequência e apresentam variabilidade em termos tecnológicos (incluindo matéria-prima, sequência de produção e morfologia);

2) Holoceno Médio: para este período, há referências cronológicas mais uma vez oriundas da região de Taió, com o sítio SC-TA-03, mas também de Alfredo Wagner, com o sítio SC-VI-13. No caso de Taió, encontram-se pontas de projétil entre o material arqueológico associado às amostras datadas. Já no caso de Alfredo Wagner, há material lítico, mas nada que esteja vinculado à produção deste objeto. Há, ainda nesta coleção, material vegetal com excelente grau de conservação. Estamos diante de contextos distintos? Infelizmente, a amostra disponível e a ausência de outros sítios que possam estar claramente associados a este período limitam nossas possibilidades interpretativas;

3) Holoceno Recente: neste período, podem ser englobados tanto sítios da região de Taió quanto 
de Alfredo Wagner, mas, como discutido no item anterior, possivelmente temos processos distintos ocorrendo nas duas áreas, em função das dinâmicas de interação estabelecidas entre grupos Jê meridionais e Guarani nessas regiões. No entanto, é fundamental reforçar que, também neste período, estão presentes sítios compostos exclusivamente por material lítico, cujos conjuntos contemplam a presença de pontas de projétil.

A partir da construção dessa 'macroestrutura' de ocupação da área, vemos que, apesar de ser possível vislumbrar distintos momentos com dinâmicas de ocupação, há uma categoria de sítio e de conjunto artefatual que perpassa todos os períodos - sítios líticos, com ou sem pontas de projétil.

Esse talvez seja, no momento, um dos principais desafios para avançarmos na compreensão das dinâmicas envolvidas no processo de ocupação do alto vale - a definição de critérios que nos possibilitem, ao mesmo tempo, articular estes sítios em caráter sistêmico e dissociálos diacronicamente. Para tanto, conforme apontado por Dias (2003), para o Rio Grande do Sul, o caminho passa necessariamente pela implementação de pesquisas que contemplem uma abordagem regional.

Aliados a isso, estudos detalhados sobre tecnologia - abordando tanto a identificação e a caracterização dos esquemas operatórios envolvidos na produção de pontas de projétil quanto a produção e a integração dos demais vestígios líticos - são capazes de trazer informações essenciais para que possamos distinguir essas indústrias no tempo através da identificação das escolhas tecnológicas (Dias, 2007).

No que se refere à ocupação Jê, uma compreensão refinada do povoamento da área demanda a realização de mais atividades de campo, tanto prospecções quanto escavações, e de laboratório, a fim de investigar se há uma ocupação diferenciada dos sítios localizados nos dois padrões de implantação identificados até então (cadeia de morros/proximidades da escarpa). Até o momento, apenas três estruturas subterrâneas foram escavadas em um sítio localizado na área, sendo que há informações sobre a existência de 45 sítios. Há também que se obter maior número de informações cronológicas.

Ademais, há que se incorporar outras categorias de sítios (abrigos sob rochas e montículos, além dos líticos a céu aberto), para que se entenda essa ocupação em termos de sistema de assentamento, bem como buscar identificar possíveis fontes de matérias-primas (rochas e argilas).

Assim, os resultados obtidos por ações realizadas em sítios de estruturas subterrâneas devem ser interpretados sob perspectiva diacrônica e multiescalar (intrassítio, microrregional e regional), considerando e enfatizando as especificidades ambientais que o contexto serrano apresenta, especialmente no que remete ao ecótono existente na fronteira Mata Atlântica/Mata de Araucárias. Isso é fundamental, visto que análises arqueobotânicas - incorporadas recentemente em pesquisas desenvolvidas em contextos Jê meridional do planalto e de outros contextos serranos (Corteletti, 2012) - têm produzido uma série de contribuições no sentido de compreender o paleoambiente, bem como aspectos relacionados à economia e à dieta, por exemplo.

Outro caminho para se compreender a espacialidade das atividades desenvolvidas por grupos Jê meridionais no Alto Vale do Itajaí do Sul consiste no investimento em melhor caracterização do processo de produção de vasilhames cerâmicos. A partir de vestígios cerâmicos coletados no sítio Tobias Wagner, foi possível realizar uma primeira ação quanto à composição química das argilas utilizadas por meio da espectrometria (Costa et al., 2017). Através da análise de maior número de coleções cerâmicas, provenientes de diferentes sítios, associadas à identificação de fontes de matérias-primas e do estudo das técnicas na produção, tornar-se-á possível perceber mais sobre a relação que os grupos Jê meridionais estabeleciam com o território. Além disso, por meio de comparações em escala maior, será possível pensar diferenças e semelhanças com outros grupos que ocuparam o planalto e o litoral, por exemplo.

No que se refere ao estudo sobre as dinâmicas de interação cultural, cremos que, para além dos encontros 
e desencontros entre grupos Jê meridionais e Guarani enfocados pelos pesquisadores nos últimos anos, é fundamental pensar na inserção de grupos caçadorescoletores nesta dinâmica. Isso não significa, de maneira alguma, tomar os sítios líticos de forma monolítica, como entidades estáticas e isoladas, que indicariam a presença de grupos caçadores-coletores através da sua associação a uma categoria arqueológica classificatória abstrata, como a Tradição Umbu.

A questão é que muitos destes sítios líticos aparecem nas mesmas áreas, há poucos metros de sítios nos quais há estruturas subterrâneas, com datas relacionadas a um contexto extremamente recente nessa longa história de ocupação do vale. Como compreender e interpretar, ao mesmo tempo, essa proximidade espacial/temporal de um lado e indicadores de uma possível continuidade tecnológica com ocupações vinculadas ao Holoceno Inicial? Essa pergunta envolve ao menos duas questões, uma de ordem teórica e outra, metodológica: a primeira seria pensarmos o que está envolvido nessa continuidade, o que ela significa, o que a sustenta e como o conhecimento vinculado a ela é produzido e transmitido; a segunda envolve pensarmos se as nossas estratégias metodológicas estão orientadas e preparadas para perceber variações ou enfatizar continuidades.

Ou seja, para avançarmos na discussão sobre interação cultural e dinâmica de povoamento do Sul do Brasil e, neste caso, especificamente, do Vale do Itajaí, é fundamental trabalharmos não só com a dinâmica estabelecida entre grupos Guarani e grupos Jê meridionais, mas também inserirmos nessa relação os grupos caçadores-coletores que ocupavam boa parte dessa região já desde o Holoceno Inicial.

Para tanto, em nossa perspectiva, há dois conceitos fundamentais que podem articular o conjunto de elementos ora mencionados, e oferecer um caminho teórico e metodológico que viabilize a flexibilização das categorias analíticas utilizadas atualmente. Esses conceitos são tecnologia e território, entendidos como um conjunto de escolhas culturais implementadas por grupos humanos que percebem, interagem e ativamente constroem os espaços em que vivem. Ou seja, artefatos, estruturas e sítios devem ser pensados de forma integrada, enquanto atores e vetores que nos possibilitem construir e compreender as relações nas quais estão imbrincados e que constituem formas particulares de territorialidade. Apesar das possíveis dificuldades para implementação, cremos ser este o caminho para incorporar a complexidade envolvida nos processos de interação cultural, que são parte indissociável da formação do registro arqueológico.

\section{AGRADECIMENTOS}

Esta pesquisa contou com financiamento do Conselho Nacional de Desenvolvimento Científico e Tecnológico (CNPq), no âmbito do edital Universal 2014 (processo 458912/2014-0), e da Coordenação de Aperfeiçoamento de Pessoal de Nível Superior (CAPES) (processos 88881.128654/2016-01 e 99999.000467/2016-02, referentes às bolsas de estudos de Lucas Bond Reis e de Fernando Silva de Almeida no exterior, respectivamente, além de bolsas CAPES/DS para ambos), bem como com o apoio do Programa de Pós-Graduação em História da UFSC. Agradecemos, especialmente, ao Sr. Altair Wagner, que gentilmente tem colaborado com a equipe do LEIA UFSC, fornecendo informações sobre a localização de sítios, colocando à disposição o Museu de Arqueologia de Lomba Alta, pelo qual é responsável. Agradecemos à comunidade de Alfredo Wagner, que tem sido muito solícita em diversas demandas necessárias da pesquisa, bem como aos alunos e aos pesquisadores de diferentes instituições (UFSC, Instituto Anchietano/Universidade do Vale do Rio dos Sinos, Universidade Federal do Piauí, Museu de Arqueologia e Etnologia da Universidade de São Paulo, Universidade Federal do Paraná, Ateliê de Conservação e Restauração de Bens Culturais Móveis da Fundação Catarinense de Cultura), que contribuíram em atividades de campo e/ou com análises laboratoriais. 


\section{REFERÊNCIAS}

ALMEIDA, Fernando Silva de. Arqueologia e história indígena na encosta de Santa Catarina: o estudo tecnológico de indústrias líticas da Tradição Umbu no Alto Vale do Itajaí. Relatório de qualificação. Florianópolis: UFSC, 2017.

ALMEIDA, Fernando Silva de. Arqueologia e história indígena na encosta de Santa Catarina: o estudo tecnológico de indústrias líticas da Tradição Umbu no Alto Vale do Itajaí. Projeto de doutorado. Florianópolis: UFSC, 2015.

BARRETO, Cristiana. A construção de um passado pré-colonial: uma breve história da arqueologia no Brasil. Revista USP, São Paulo, n. 44, p. 32-51, dez.-fev. 1999-2000. DOI: https://doi.org/10.11606/ issn.2316-9036.v0i44p32-51.

BEBER, Marcus Vinícius. O sistema de assentamento dos grupos ceramistas do planalto sul-brasileiro: o caso da tradição Taquara/ Itararé. 2004. 289 f. Tese (Doutorado em História) - Universidade do Vale do Rio dos Sinos, São Leopoldo, 2004.

BEHLING, Hermann; PILLAR, Valerio DePatta; ORLÓCI, László; BAUERMANN, Soraia Girard. Late Quaternary Araucaria forest, grassland (Campos), fire and climate dynamics, studied by high-resolution pollen, charcoal and multivariate analysis of the Cambará do Sul core in southern Brazil. Palaeogeography, Palaeoclimatology, Palaeoecology, Amsterdam, v. 203, n. 3-4, p. 277-297, Feb. 2004. DOI: https://doi.org/10.1016/S00310182(03)00687-4.

BENEDET, Cristina; GUCHÉRT, Aline; DIAS, J.; CABRAL, Cristine; ARNOLD, J.; ROSA, R.; SANTOS, S.; SCHULLER, Fernanda. Atlas ambiental escolar do município de Alfredo Wagner, SC. Florianópolis: NEA/UFSC, 2008.

BONOMO, Mariano; ANGRIZANI, Rodrigo Costa; APOLINAIRE, Eduardo; NOELLI, Francisco Silva. A model for the Guaraní expansion in the La Plata Basin and littoral zone of southern Brazil. Quaternary International, Amsterdam, v. 356, p. 54-73, Jan. 2015. DOI: https://doi.org/10.1016/j.quaint.2014.10.050.

CONSCIÊNCIA CONSULTORIA CIENTÍFICA. Projeto de salvamento arqueológico na área de implantação da LT 69kv, PCH Ibirama. Sítios Operário, Rio Selin I e Rio Selin II. Ibirama, Alto Vale do Itajaí, SC. Relatório final. Florianópolis, 2014.

COPÉ, Silvia Moehlecke. As paisagens culturais do planalto sulbrasileiro. A aplicação da abordagem da arqueologia da paisagem ao estudo dos sítios arqueológicos do planalto sul-brasileiro: estudos de caso no Rio Grande do Sul. In: MACEDO, J.; ANDRADE, R.; TERRA, C. (Org.). Arqueologia na paisagem: novos valores, dilemas e instrumentais. Rio de Janeiro: Rio Books, 2012. p. 92-121.

COPÉ, Silvia Moehlecke. Narrativas espaciais das ações humanas: história e aplicação da arqueologia espacial como teoria de médio alcance: o caso das estruturas semisubterrâneas do planalto sulbrasileiro. Revista de Arqueologia, Juiz de Fora, v. 19, p. 111-123, 2006.
CORTELETTI, Rafael. Projeto Arqueológico Alto Canoas PARACA: um estudo da presença Jê no planalto catarinense. 2012. 342 f. Tese (Doutorado em Arqueologia) - Universidade de São Paulo, São Paulo, 2012.

COSTA, Thiago G.; CORREIA, Marcelino D. M.; REIS, Lucas Bond; SANTOS, Sailer S. dos; MACHADO, Juliana Salles; BUENO, Lucas; MULLER, Isabela da Silva. Spectroscopic characterization of recently excavated archaeological potsherds of Taquara/Itararé tradition from Tobias Wagner site (Santa Catarina - Brazil). Journal of Archaeological Science: Reports, Amsterdam, v. 12, p. 561-568, Apr. 2017. DOI: https://doi. org/10.1016/j.jasrep.2017.03.014.

DE MASI, Marco Aurélio Nadal. Arqueologia das terras altas do sul do Brasil: o baixo vale do rio Canoas, SC. In: DE MASI, Marco Aurélio Nadal (Org.). Xokleng 2860 a.C.: as terras altas do sul do Brasil. Tubarão (SC): Ed. Unisul, 2006. p. 47-75.

DE MASI, Marco Aurélio Nadal. Pescadores Coletores da Costa Sul do Brasil. Pesquisas-Antropologia, São Leopoldo, n. 57, p. $1-136,2001$

DIAS, Adriana Schmidt; HOELTZ, Sirlei Elaine. Indústrias líticas em contexto: o problema Humaitá na arqueologia Sul brasileira. Revista de Arqueologia, Pelotas, v. 23, n. 2, p. 40-67, sem. 2010. DOI: https://doi.org/10.24885/sab.v23i2.299.

DIAS, Adriana Schmidt. Novas perguntas para um velho problema: escolhas tecnológicas como índices para o estudo de fronteiras e identidades sociais no registro arqueológico. Boletim do Museu Paraense Emílio Goeldi. Ciências Humanas, Belém, v. 2, n. 1, p. 59-76, jan.-abr. 2007. DOI: http://dx.doi.org/10.1590/S198181222007000100005.

DIAS, Adriana Schmidt; JACOBUS, André Luiz. Quão antigo é o povoamento do sul do Brasil? Revista do CEPA, Santa Cruz do Sul, v. 27, n. 38, p. 39-67, sem. 2003.

DIAS, Adriana Schmidt. Sistemas de assentamento e estilo tecnológico: uma proposta interpretativa para a ocupação précolonial do alto vale do rio dos Sinos, Rio Grande do Sul. 2003. $401 \mathrm{f}$. Tese (Doutorado em Arqueologia) - Universidade de São Paulo, São Paulo, 2003.

DIAS, Adriana Schmidt. Repensando a tradição Umbu a partir de um estudo de caso. 1994. 170 f. Dissertação (Mestrado em História) - Pontifícia Universidade Católica do Rio Grande do Sul, Porto Alegre, 1994.

EBLE, Alroíno B. Problemas arqueológicos da região do Alto Vale do Itajaí. Anais do Museu de Antropologia da UFSC, Florianópolis, v. 6, n. 6, p. 41-49, 1973a.

EBLE, Alroíno B. Identificação arqueológica de padrões de povoamento e de subsistência na região do Alto Vale do Itajaí Santa Catarina - Brasil. Anais do Museu de Antropologia da UFSC, Florianópolis, v. 6, n. 6, p. 36-74, 1973 b. 
FARIAS, Deisi Scunderlick Eloy de. Distribuição e padrão de assentamento: propostas para os sítios da tradição Umbu na encosta de Santa Catarina. 2005. 364 f. Tese (Doutorado em História) - Pontifícia Universidade Católica do Rio Grande do Sul, Porto Alegre, 2005.

HOELTZ, Sirlei Elaine; LOURDEAU, Antoine; VIANA, Sibeli A. Um novo conceito de lascamento no Sul do Brasil: debitagem laminar na foz do rio Chapecó (SC/RS). Revista do Museu de Arqueologia e Etnologia, São Paulo, n. 25, p. 3-19, dez. 2015. DOI: https://doi. org/10.11606/issn.2448-1750.revmae.2015.114852.

HOELTZ, Sirlei Elaine. Tecnologia lítica: uma proposta de leitura para a compreensão das indústrias do Rio Grande do Sul, Brasil, em tempos remotos. 2005. 464 f. Tese (Doutorado em História) - Pontifícia Universidade Católica do Rio Grande do Sul, Porto Alegre, 2005.

IRIARTE, José; BEHLING, Hermann. The expansion of Araucaria forest in the southern Brazilian highlands during the last 4000 years and its implications for the development of the Taquara/Itararé Tradition. Environmental Archaeology, Oxfordshire, v. 12, n. 2, p. 115-127, July 2007. DOI: https://doi.org/10.1179/174963107×226390.

LABORATÓRIO DE ESTUDOS INTERDISCIPLINARES EM ARQUEOLOGIA/UNIVERSIDADE FEDERAL DE SANTA CATARINA (LEIA/UFSC). Florianópolis, 2018. Disponível em: $<$ http://leia.ufsc.br/>. Acesso em: 1 abr. 2018.

LOURDEAU, Antoine; CARBONERA, Mirian; SANTOS, Marcos César Pereira; HOELTZ, Sirlei; FONTUGNE, Michel; HATTÉ, Christine; SILVA, Sergio Francisco Serafim Monteiro da; ROSINA, Pierluigi; LUCAS, Lívia de Oliveira E.; COSTA, Amélie da; FOUCHER, Cécile; RAMALHO, Juliana Betarello; KUCZKOVSKI, Francieli; CAMPOS, Juliano Bitencourt; VIANA, Sibeli Aparecida; HERBERTS, Ana Lucia. Pré-história na foz do rio Chapecó. Revista Cadernos do Ceom, Chapecó, v. 29, n. 45, p. 220-242, dez. 2016. DOI: http://dx.doi.org/10.22562/2016.45.09.

LOURDEAU, Antoine; HOELTZ, Sirlei Elaine; VIANA, Sibeli A. Early Holocene blade technology in southern Brazil. Journal of Anthropological Archaeology, Amsterdam, v. 35, p. 190-201, Sep. 2014. DOI: https://doi.org/10.1016/j.jaa.2014.06.003.

MACHADO, Juliana Salles. Ũ TÕ DÉN TXI KABEL, aqueles que contam histórias: memória e território Laklãnõ (Xokleng). Relatório final. São Paulo: FAPESP, 2016.

MENDONÇA DE SOUZA, Alfredo. História da Arqueologia no Brasil. Pesquisas-Antropologia, São Leopoldo, n. 46, p. 1-157, 1991.

NOELLI, Francisco Silva; SOUZA, José Gregório de. Novas perspectivas para a cartografia arqueológica Jê no Brasil meridional. Boletim do Museu Paraense Emílio Goeldi. Ciências Humanas, Belém, v. 12, n. 1, p. 57-84, jan.-abr. 2017. DOI: http://dx.doi.org/ 10.1590/1981.81222017000100004.
NOELLI, Francisco Silva. O mapa arqueológico dos povos Jê no sul do Brasil. In: TOMMASINO, Kimiye; MOTTA, Lúcio Tadeu; NOELLI, Francisco Silva (Org.). Novas contribuições aos estudos interdisciplinares dos Kaingang. Londrina: EDUEL, 2004. p. 18-56.

NOELLI, Francisco Silva. A ocupação humana na região Sul do Brasil: arqueologia, debates e perspectivas - 1872-2000. Revista USP, São Paulo, n. 44, p. 218-269, dez.-fev. 1999-2000. DOI: https://doi.org/10.11606/issn.2316-9036.v0i44p218-269.

NOELLI, Francisco Silva. Repensando os rótulos e a história dos Jê no sul do Brasil a partir de uma interpretação interdisciplinar. Revista do Museu de Arqueologia e Etnologia, São Paulo, p. 285302, irreg. 1999. DOI: https://doi.org/10.11606/issn.2594-5939. revmaesupl.1999.113474.

NOELLI, Francisco Silva. Os Jê do Brasil meridional e a antigüidade da agricultura: elementos da lingüística, arqueologia e etnografia. Estudos Ibero-Americanos, Porto Alegre, v. 22, n. 1, p. 13-25, jun. 1996. DOI: http://dx.doi.org/10.15448/1980-864X.1996.1.28773.

OKUMURA, Mercedes; ARAUJO, Astolfo Gomes de Mello. Long-term cultural stability in hunter-gatherers: a case study using traditional and geometric morphometric analysis of lithic stemmed bifacial points from Southern Brazil. Journal of Archaeological Science, Amsterdam, v. 45, p. 59-71, May 2014. DOI: https://doi. org/10.1016/j.jas.2014.02.009.

OPPITZ, Gabriela. Vivendo a paisagem: contribuições transdisciplinares para o estudo do contexto regional de sambaquis do litoral central de Santa Catarina. 2011. 137 f. Monografia (Graduação em História) - Universidade Federal de Santa Catarina, Florianópolis, 2011.

PARELLADA, Claudia Inês. Estudo arqueológico no alto vale do rio Ribeira: área do gasoduto Bolívia-Brasil, trecho X, Paraná. 2005. 272 f. Tese (Doutorado em Arqueologia) - Universidade de São Paulo, São Paulo, 2005.

PIAZZA, Walter. Dados à arqueologia do litoral norte e do planalto de Canoinhas. Programa Nacional de Pesquisas Arqueológicas, Belém, v. 5, p. 53-63, 1974.

PIAZZA, Walter. Dados complementares à arqueologia do vale do Uruguai. Programa Nacional de Pesquisas Arqueológicas, Belém, v. 4, p. 71-86, 1971.

PIAZZA, Walter. Memória arqueológica sobre o Vale do Itajaí (Santa Catarina-Brasil). Florianópolis: MArquE/UFSC, 1966. Mimeografado.

PROUS, André; PIAZZA, Walter F. Documents pour la prehistoire du Bresil Meridional: L'État de Santa Catarina. Paris: Ecole des Hautes Etudes en Science Sociales, 1977. 
REIS, Lucas Bond; BEE, Bruno Jorge; CRUZ, Aline Pereira. Relatório de atividades de campo entre 21 e 24 de março de 2018 no Alto Vale do Itajaí do Sul. Projeto Territorialidades Ameríndias no Alto Vale do Itajaí. Um olhar a partir da Arqueologia, da Ecologia e da Paleontologia. Florianópolis: LEIA/UFSC, 2018.

REIS, Lucas Bond. Para uma história jê meridional na longa duração: o contexto em Alfredo Wagner (SC) e a sua inserção regional. 2015. 377 f. Dissertação (Mestrado em História) - Centro de Filosofia e Ciências Humanas, Universidade Federal de Santa Catarina, Florianópolis, 2015.

REIS, Maurício Sedrez dos; LADIO, Ana; PERONI, Nivaldo. Landscapes with Araucaria in South America: evidence for a cultural dimension. Ecology and Society, Wolfville, v. 19, n. 2, p. 1-14, June 2014. DOI: http://dx.doi.org/10.5751/ES-06163-190243.

RIRIS, Philip; CORTELETTI, Rafael. A new record of Pre-Columbian engravings in Urubici (SC), Brazil using polynomial texture mapping. Internet Archaeology, United Kingdom, n. 38, p. 1-25, Feb. 2015. DOI: https://doi.org/10.11141/ia.38.7.

ROBINSON, Mark; SOUZA, Jonas Gregório de; MAEZUMI, S. Yoshi; CÁRDENAS, Macarena; PESSENDA, Luiz; PRUFER, Keith; CORTELETTI, Rafael; SCUNDERLICK, Deisi; MAYLE, Franci Edward; DE BLASIS, Paulo; IRIARTE, José. Uncoupling human and climate drivers of late Holocene vegetation change in southern Brazil. Scientific Reports, London, v. 8, n. 7800, p. 1-10, May 2018. DOI: https://doi.org/10.1038/s41598-018-24429-5.

$\mathrm{ROHR}$, João Alfredo. Sítios arqueológicos de Santa Catarina. Anais do Museu de Antropologia da UFSC, Florianópolis, v. 16, n. 17, p. 77-168, dez. 1984.

ROHR, João Alfredo. Os sítios arqueológicos do Planalto Catarinense, Brasil. Pesquisas-Antropologia, São Leopoldo, n. 24, p. $1-56,1971$

ROHR, João Alfredo. O sítio arqueológico de Alfredo Wagner: SCVI-13. Pesquisas-Antropologia, São Leopoldo, n. 17, p. 1-24, 1967.

SANTOS, Silvio Coelho dos. Índios e brancos no sul do Brasil: a dramática experiência dos Xokleng. Florianópolis: Edeme, 1973.

SCHERER, Luciane Zanenga. Análise dos remanescentes ósseos humanos do sítio arqueológico Alto Jararaca II, Alfredo Wagner. In: REIS, Lucas Bond. Para uma história jê meridional na longa duração: o contexto em Alfredo Wagner (SC) e a sua inserção regional. 2015. 377 f. Dissertação (Mestrado em História) - Centro de Filosofia e Ciências Humanas, Universidade Federal de Santa Catarina, Florianópolis, 2015. p. 347-356.
SCHMITZ, Pedro Ignácio; ARNT, Fúlvio Vinícius; BEBER, Marcus Vinícius; ROSA, André Osório; ROGGE, Jairo Henrique. Taió, no vale do Rio Itajaí, SC: o encontro de antigos caçadores com as casas subterrâneas. Pesquisas-Antropologia, São Leopoldo, n. 67 , p. $185-320,2009$.

SCHMITZ, Pedro Ignácio; ROGGE, Jairo H.; ROSA, André O.; BEBER, Marcus Vinícius; MAUHS, Julian; ARNT, Fúlvio Vinícius. O Projeto Vacaria: casas subterrâneas no planalto rio-grandense. Pesquisas-Antroplogia, São Leopoldo, n. 58, p. 11-105, 2002.

SCHMITZ, Pedro Ignácio. Áreas arqueológicas do litoral e do planalto do Brasil. Revista do Museu de Arqueologia e Etnologia, São Paulo, n. 1, p. 3-20, jun. 1991. DOI: https://doi.org/10.11606/ issn.2448-1750.revmae.1991.107913.

SCHMITZ, Pedro Ignácio; BROCHADO, José J. J. P. Datos para una secuencia cultural del Estado de Rio Grande do Sul, Brasil. Gabinete de Arqueologia Publicações, v. 2, p. 1-20, 1972.

SCHRÖDER, Paulo Henrique. Inventário e caracterização espeleológica preliminar das cavidades na bacia do Caeté, município de Alfredo Wagner/SC. 2005. 168 f. Monografia (Graduação em Geografia) - Universidade Federal de Santa Catarina, Florianópolis, 2005.

SOUZA, Jonas Gregório de; CORTELETTI, Rafael; ROBINSON, Mark; IRIARTE, José. The genesis of monuments: resisting outsiders in the contested landscapes of southern Brazil. Journal of Anthropological Archaeology, Amsterdam, v. 41, p. 196-212, Mar. 2016. DOI: https://doi.org/10.1016/j.jaa.2016.01.003.

SUÁREZ, Rafael. The human colonization of the Southeast Plains of South America: climatic conditions, technological innovations and the peopling of Uruguay and south of Brazil. Quaternary International, Amsterdam, v. 431, p. 181-193, Feb. 2016. Part B. DOI: https://doi. org/10.1016/j.quaint.2016.02.018.

WAGNER, Altair. Alfredo Wagner: terra, água e índios. Florianópolis: Fundação Alfredo Wagner, 2002.

ZEDEÑO, María Nieves. The archaeology of territory and territoriality. In: DAVID, Bruno; THOMAS, Julian (Ed.). Handbook of landscape archaeology. Walnut Creek (CA): Left Coast Press, 2008. p. 210-217.

ZEDEÑO, María Nieves. Landscapes, land use, and the history of territory formation: an example from the Puebloan southwest. Journal of Archaeological Method and Theory, Berlim, v. 4. n. 1, p. 67-103, Mar. 1997.

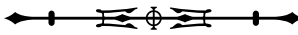


